\title{
Repurposing Sigma-1 Receptor Ligands for COVID-19 Therapy?
}

\author{
José Miguel Vela ${ }^{* t}$ \\ Drug Discovery and Preclinical Development, ESTEVE Pharmaceuticals, Barcelona, Spain
}

\section{OPEN ACCESS}

Edited by:

Rafael Maldonado,

Pompeu Fabra University, Spain

Reviewed by:

Srikanta Dash,

Tulane University, United States Aditi Banerjee, University of Maryland, Baltimore, United States

*Correspondence:

José Miguel Vela

jvela@welab.barcelona

tPresent address:

WeLab, Parc Cientific Barcelona,

Barcelona, Spain

Specialty section:

This article was submitted to

Experimental Pharmacology

and Drug Discovery,

a section of the journal

Frontiers in Pharmacology

Received: 11 July 2020

Accepted: 30 September 2020

Published: 09 November 2020

Citation:

Vela JM (2020) Repurposing Sigma-1 Receptor Ligands for COVID-19

Therapy?.

Front. Pharmacol. 11:582310. doi: 10.3389/fphar.2020.582310
Outbreaks of emerging infections, such as COVID-19 pandemic especially, confront health professionals with the unique challenge of treating patients. With no time to discover new drugs, repurposing of approved drugs or in clinical development is likely the only solution. Replication of coronaviruses (CoVs) occurs in a modified membranous compartment derived from the endoplasmic reticulum (ER), causes host cell ER stress and activates pathways to facilitate adaptation of the host cell machinery to viral needs. Accordingly, modulation of ER remodeling and ER stress response might be pivotal in elucidating CoVhost interactions and provide a rationale for new therapeutic, host-based antiviral approaches. The sigma-1 receptor (Sig-1R) is a ligand-operated, ER membranebound chaperone that acts as an upstream modulator of ER stress and thus a candidate host protein for host-based repurposing approaches to treat COVID-19 patients. Sig-1R ligands are frequently identified in in vitro drug repurposing screens aiming to identify antiviral compounds against CoVs, including severe acute respiratory syndrome CoV-2 (SARS-CoV-2). Sig-1R regulates key mechanisms of the adaptive host cell stress response and takes part in early steps of viral replication. It is enriched in lipid rafts and detergent-resistant ER membranes, where it colocalizes with viral replicase proteins. Indeed, the non-structural SARS-CoV-2 protein Nsp6 interacts with Sig-1R. The activity of Sig-1R ligands against COVID-19 remains to be specifically assessed in clinical trials. This review provides a rationale for targeting Sig-1R as a host-based drug repurposing approach to treat COVID-19 patients. Evidence gained using Sig-1R ligands in unbiased in vitro antiviral drug screens and the potential mechanisms underlying the modulatory effect of Sig-1R on the host cell response are discussed. Targeting Sig-1R is not expected to reduce dramatically established viral replication, but it might interfere with early steps of virus-induced host cell reprogramming, aid to slow down the course of infection, prevent the aggravation of the disease and/or allow a time window to mature a protective immune response. Sig-1R-based medicines could provide benefit not only as early intervention, preventive but also as adjuvant therapy.

Keywords: COVID-19, SARS-CoV-2, anti-viral, repurposed drugs, drug repurposing, sigma-1 receptor, ER stress, viral replication 


\section{INTRODUCTION}

The newly emerged 2019 novel coronavirus (CoV), named as severe acute respiratory syndrome CoV-2 (SARS-CoV-2), has been associated with high infection rates and has spread rapidly to become a pandemic (COVID-19 pandemic) since its identification in patients with severe pneumonia in Wuhan, China. Unfortunately, no vaccine has yet been approved to treat human CoVs and the discovery and development of new drugs will require years. Accordingly, repurposing of approved drugs or drugs in clinical development has emerged as a feasible approach to reduce the time compared to de novo drug discovery and ultimately to provide a faster treatment option for COVID-19 patients.

$\mathrm{CoV}$ replication is structurally and functionally associated with the endoplasmic reticulum (ER) (Sola et al., 2015), and $\mathrm{CoV}$ infection is well known to activate pathways to facilitate adaptation of ER stress to viral needs. These embrace hijacking the host cell ER stress responses to modulate protein translation, ER protein folding capacity, ER-associated degradation (ERAD), including autophagy, and apoptotic cell death (Fung and Liu, 2014; Fung et al., 2014a). Therefore, modulation of ER stress response might be pivotal in elucidating CoV-host interactions and might provide the rationale for new therapeutic approaches.

The sigma-1 receptor (Sig-1R) acts as an upstream modulator of ER stress. Sig-1R is a ligand-operated, membrane-bound chaperone that normally reside at the ER-mitochondrion contact called the (mitochondrion-associated ER membrane (MAM), where it regulates ER-mitochondrion signaling and ER-nucleus crosstalk (Hayashi, 2019). Mitochondrial function regulation by Sig-1R includes bioenergetics and free radical generation/oxidative stress. When cells undergo stress, Sig-1R translocates from the MAM to the ER reticular network and plasma membrane to regulate a variety of functional proteins. Via its molecular chaperone activity, the Sig- $1 \mathrm{R}$ regulates protein folding/degradation, calcium $\left(\mathrm{Ca}^{2+}\right)$ homeostasis, ER stress responses, autophagy, and ultimately cell survival (Hayashi and Su, 2007; Su et al., 2010; Schrock et al., 2013; Vollrath et al., 2014; Hayashi, 2019; Delprat et al., 2020). Interestingly, its chaperone activity can be activated or inhibited by synthetic Sig-1R ligands in an agonist-antagonist manner.

As it regards to its potential antiviral activity, Sig-1R ligands are frequently identified in in vitro drug repurposing screens aiming to identify antiviral compounds against SARS-CoV-2 and other CoVs. Mechanistically, Sig-1R is involved in cellular stress pathways which are used by viruses to promote viral replication (Vasallo and Gastaminza, 2015). Accordingly, Sig-1R has been shown to colocalize with viral replicase proteins in membranous compartments (Friesland et al., 2013), and it has been recently reported that the non-structural (NS) SARS-CoV-2 protein Nsp6 directly interacts with Sig-1R (Gordon et al., 2020). Sig-1R is expressed at substantial density in rodent (Lever et al., 2015) and human (Stone et al., 2006) lungs.

Here pharmacological and genetic data supporting a role for Sig-1R in viral infection are collected and summarized, with a focus on $\mathrm{CoV}$ in general and SARS-CoV-2 in particular. Targeting Sig-1R is identified as a potential drug repurposing approach to treat COVID-19 patients that, unlike virus-targeted antiviral agents, addresses adaptive cellular mechanisms of host cells that are crucial for viral infection.

\section{SIGMA-1 RECEPTOR LIGANDS EXERT ANTIVIRAL ACTIVITY}

\section{Pharmacology Findings Against Non-Coronaviruses}

The first insight about a potential role for Sig-1R ligands as antivirals was probably published in 1984 (Nemerow and Cooper, 1984). In this study, several phenothiazines, including trifluoperazine, chlorpromazine, prochlorpromazine and promethazine as well haloperidol (non-phenothiazine but butyrophenone) were shown to inhibit infection of $\mathrm{B}$ lymphocytes by a human herpesvirus, Epstein-Barr virus (EBV). By this time sigma was just starting to be considered a separate binding site from phencyclidine and $\mathrm{mu}$ and delta opioid receptors to which (+)-[ $\left[{ }^{3} \mathrm{H}\right] \mathrm{SKF} 10,047$ binds (Su, 1982; Tam, 1983). Also by this time, different non-selective neuroleptics including haloperidol, trifluoperazine, chlorpromazine and promethazine were shown to bind this sigma site (Su, 1982; Tam and Cook, 1984) (Table 1), but this was twelve years before the Sig-1R was first cloned (Hanner et al., 1996). Accordingly, authors did not mention sigma mechanisms and attributed the antiviral efficacy of these drugs to effects on calmodulin-regulated cellular endocytic processes involved in early stages of EBV infection. These non-selective Sig-1R ligands were found later to exert antiviral activity against other viruses, including coronaviruses (Table $\mathbf{1}$ ).

Drugs binding Sig-1R showing antiviral activity were identified in three in vitro screening studies aiming to discover inhibitors targeting different steps of Hepatitis C virus (HCV) infection. In the first study, a set of 446 compounds from the National Institutes of Health Clinical Collection were assayed for their ability to inhibit HCV infection of human hepatocarcinoma Huh-7 cells in vitro (Gastaminza et al., 2010). Compounds were screened in a cell-based assay in an unbiased manner, independent on target specificity or mechanism of action. Among the 446 clinically approved small molecules assayed, 33 compounds displayed antiviral activity $(>85 \%$ reduction in $\mathrm{HCV}$ infection of Huh-7 cells, as compared to the vehicle DMSO control) in the absence of cytotoxicity at low micromolar and submicromolar concentrations. Compounds targeted several aspects of $\mathrm{HCV}$ infection, including entry, replication, and assembly. Some of the active antiviral compounds were already known to have antiviral activity, but the ability of most of them to inhibit HCV infection was unexpected. Among the 33 active compounds, 19 compounds (cyproheptadine, toremifene, fluphenazine, trifluoperazine, CGS 12066B, prochlorperazine, doxepin, ketotifen, amiodarone, lofepramine, rimcazole, clobenpropit, salmeterol, azelastine, desloratadine, indatraline, haloperidol, benproperine and carvedilol) bind to Sig-1R with high to moderate affinity (Table 1). All of them are non-selective and bind primarily to molecular targets other than Sig-1R, but it is remarkable that near 
TABLE 1 | Drug class.

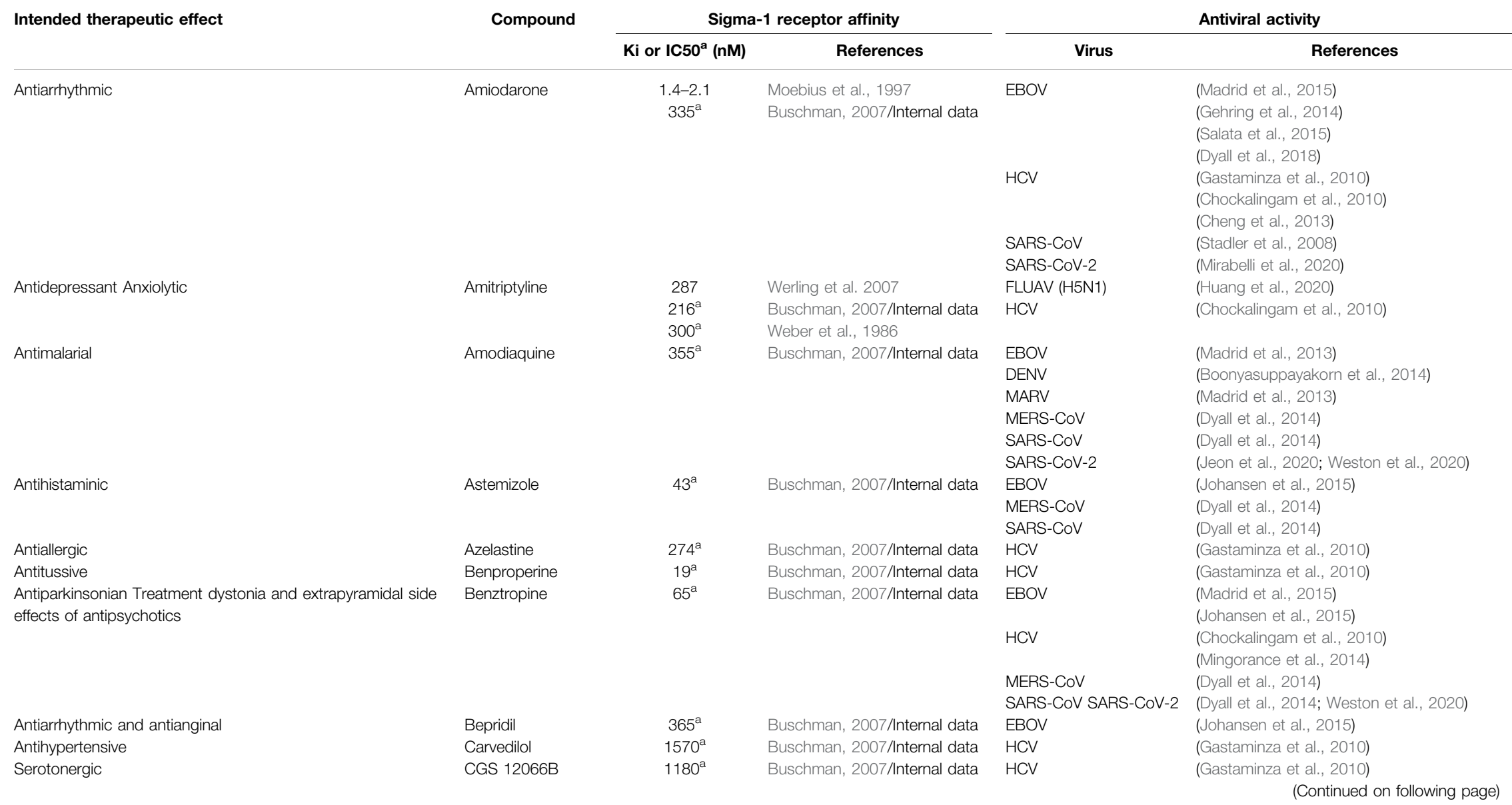


TABLE 1 | (Continued) Drug class.

Intended therapeutic effect

Antimalarial

Chloroquine

Compound

Ki or IC $50^{\mathrm{a}}$ (nM)

Antihistaminic Antiparkinsonian

Antipsychotic

Anthistaminic Antivertigo

Antihistaminic

Neuroprotectant

Estrogen receptor modulator

Ovulation stimulator

Antidepressant

Antihistaminic Antitussive

\section{Chlorphenoxamine}

Chlorpromazine

Cinnarizine

Clemastine

Clobenpropit

Clomiphene

Clomipramine

Cloperastine
Gregori-Puigjané et al., 2012 SARS-CoV-2
108.6

$2300^{\mathrm{a}}$

PDSP Ki Database certified data CCHFV
Buschman, 2007/Internal data CHIKV

DENV

EBOV

FLUAV (H1N1
FLUAV (H5N1)

HCoV-229E

HCOV-OC43

HIV-1

MARV

MERS-COV

SARS-COV

SARS-CoV-2 $1760^{\mathrm{a}}$

146

$200^{\mathrm{a}}$
$1070^{\mathrm{a}}$

$1070^{\mathrm{a}}$

$119^{\mathrm{a}}$

67
$505^{\mathrm{a}}$

$1080^{\circ}$

1080

$4.7-12$

$195^{\mathrm{a}}$

$195^{\mathrm{a}}$

20
Buschman, 2007/Internal data

Tam and Cook, 1984

Lang et al., 1994

Buschman, 2007/Internal data

MERS-COV

SARS-COV

CCHFV

CHIKV

EBV

FLUAV

HCoV-229E

$\mathrm{HCV}$

MERS-COV

SARS-CoVSARS-CoV-2

Klein and Musacchio, 1989

Buschman, 2007/Internal data

Gregori-Puigjané et al., 2012

Buschman, 2007/Internal data

Buschman, 2007/Internal data

Moebius et al., 1997

Buschman, 2007/Internal data

Buschman, 2007/Internal data

$\mathrm{HCV}$

EBOV

$\mathrm{HCV}$

MERS-COV

SARS-COV SARS

HCV $277^{\mathrm{a}} \quad$ Buschman, 2007/Internal data

Antiviral activity

References

(Ferraris et al., 2015)

(Bassetto et al., 2013)

(Pohjala et al., 2011)

(Farias et al., 2013)

(Madrid et al., 2013)

(Madrid et al., 2015)

(Ooi et al., 2006)

(de et al., 2013)

(Keyaerts et al., 2009)

(Sevacts et a., 2009)

(Madrid et al., 2013)

(de Wilde et al., 2014)

(Dyall et al., 2014)

(de Wilde et al., 2014)

(Keyaerts et al., 2004)

(Dyall et al., 2014)

(Yao et al., 2020)

(Jeon et al., 2020; Weston et al., 2020)

(Dyall et al., 2014)

(Dyall et al., 2014)

(Ferraris et al., 2015)

(Pohjala et al., 2011)

(Nemerow and Cooper, 1984)

(Nugent and Shanley, 1984)

(de Wilde et al., 2014)

(Mingorance et al., 2014)

(Dyall et al., 2014)

(de Wilde et al., 2014)

Dall et al., 2014)

(Jeon et al., 2020; Weston et al., 2020)

(Chockalingam et al., 2010)

(Johansen et al., 2015)

(Gordon et al., 2020)

(Gastaminza et al., 2010)

(Madrid et al., 2015)

(Johansen et al., 2013; Johansen et al., 2015) (Murakami et al., 2013)

(Mingorance et al., 2014)

(Johansen et al., 2015)

(Mingorance et al., 2014)

(Dyall et al., 2014) 
TABLE 1 | (Continued) Drug class.

\section{Intended therapeutic effect}

\section{Antifungal}

Antiallergic Antihistaminic

Antidepressant

\section{Antiallergic}

Antidepressant

Selective sigma-1 receptor antagonist

Antimigraine

Antidepressant

Antipsychotic

Antipsychotic

Antipsychotic

Antipsychotic

Antimalarial

Antiallergic

Antihistaminic

Anxiolytic

Neuroprotectant Anticonvulsant Antihypertensive

Antidepressant

Compound
Cycloheximide
Cyproheptadine
Desipramine
Desloratadine
Doxepin
E-52862 (S1RA)
Flunarizine
Fluoxetine
Flupentixol
Fluphenazine

Fluspirilene

Haloperidol

Hydroxychloroquine

Ifenprodil

Imipramine

\section{Sigma-1 receptor affinity}

Ki or IC50 ${ }^{\mathrm{a}}(\mathrm{nM})$ $1030^{\mathrm{a}}$

$284^{\mathrm{a}}$

930

930

190

1987

$1510^{\mathrm{a}}$
$394^{\mathrm{a}}$

17

17
$28^{\mathrm{a}}$

$28^{\mathrm{a}}$
240

$949^{\mathrm{a}}$

$70^{\mathrm{a}}$

13
62
$109^{a}$

$109^{a}$

150

$380^{\mathrm{a}}$
$563^{\mathrm{a}}$

$563^{\mathrm{a}}$
0.2

0.2
1.1

$1.1^{\mathrm{a}}$

1.2

2.4

3

$6.5-7.3$

$17^{\mathrm{a}}$

$73^{\mathrm{a}}$
$2120^{\mathrm{a}}$
Buschman, 2007/Internal data

Buschman, 2007/Internal data

He et al., 2012

Buschman, 2007/Internal data

Narita et al., 1996

Buschman, 2007/Internal data Buschman, 2007/Internal data

Romero et al., 2012

Buschman 2007/Internal data

Narita et al., 1996

Buschman, 2007/Internal data

Buschman, 2007/Internal data

Tam and Cook, 1984

Largent et al., 1984

Buschman, 2007/Internal data

Schotte et al., 1996

Contreras et al., 1990

Buschman, 2007/Internal data

Hanner et al., 1996

Schotte et al., 1996

Lang et al., 1994

Akunne et al., 1997

Largent et al., 1984

Tam and Cook, 1984

Su, 1991

Weber et al., 1986

Buschman, 2007/Internal data

Buschman, 2007/Internal data

DENV

HIV-1

MERS-COV

SARS-COV

SARS-COV-2

$342^{\mathrm{a}}$
46

46

1.02

$2-2$
$5.5^{\mathrm{a}}$

$5.5^{\mathrm{a}}$
$28-34$

343

343
$529^{\mathrm{a}}$

$\mathrm{HCV}$

CHIKV

EBOV

EBOV

MERS-COV

HCV

MERS-COV

SARS-COV

Klein and Musacchio, 1989

$\mathrm{HCV}$

Gitto et al., 2014

Hanner et al., 1996

FLUAV (H5N1)

Buschman, 2007/Internal data

Su, 1991

Narita et al., $1996 \quad$ HCV
Antiviral activity

Virus References

MERS-CoV (Dyall et al., 2014

SARS-CoV (Dyall et al., 2014

HCV (Gastaminza et al., 2010)

(Chockalingam et al., 2010)

(Mirabelli et al., 2020)

HCV (Chockalingam et al., 2010)

(Mingorance et al., 2014)

(Johansen et al., 2015)

(Johansen et al., 2015)

(Gastaminza et al., 2010)

(Chockalingam et al., 2010)

(Dyall et al., 2014)

SARS-CoV SARS-CoV-2 (Dyall et al., 2014; Weston et al., 2020)

(Dyall et al., 2014)

(Dyall et al., 2014)

(Weston et al., 2020)

(Nemerow and Cooper, 1984)

(Gastaminza et al., 2010)

(Dyall et al., 2014)

(Dyall et al., 2014)

(Gordon et al., 2020)

(Wang et al., 2015)

(Sperber et al., 1993)

(Dyall et al., 2014)

(Gordon et al 2020)

(Yao et al., 2020)

(Mirabelli et al., 2020; Weston et al., 2020)

(Mingorance et al., 201)4

(Zhang et al., 2019)

(Chockalingam et al., 2010)

(Mingorance et al., 2014)

(Continued on following page) 
TABLE 1 | (Continued) Drug class.

\section{Intended therapeutic effect}

Antiadictive

Antidepressant

Antimigraine

Antidiarrheal

Antidepressant

Antimalarial

Maprotiline

Mefloquine

\section{Antihistaminic}

Sigma ligand

Sigma ligand

Antipsychotic Antiemetic Anxiolytic

PB28
Methdilazine

PD-144418

Perphenazine

Antipsychotic Treatment of Tourette syndrome and resistant tics Pimozide

\section{Antipsychotic}

Antipsychotic Antiemetic Anxiolytic

Endogenous steroid Menopausal hormone therapy

Antiallergic Antihistaminic

Antidepressant

Antimalarial

Antiarrhythmic

Serotonergic

Estrogen receptor modulator Treatment of osteoporosis in

postmenopausal women

Progesterone

Promethazine

Protriptyline

Quinacrine

Quinidine

Raloxifene

\section{Sigma-1 receptor affinity}

Ki or IC50 ${ }^{\mathrm{a}}(\mathrm{nM})$

$737^{\mathrm{a}}$

$3800^{\mathrm{a}}$
2520

References

\section{Buschman, 2007/Internal data} Buschman, 2007/Internal data HCV PDSP Ki Database certified data $\mathrm{HCV}$

$100 \%$ inh. at $10 \boldsymbol{\mu M}$ Buschman, 2007/Internal data

$37^{\mathrm{a}} \quad$ Buschman, 2007/Internal data

$37^{\mathrm{a}}$
271

Buschman, 2007/Internal data

Prochlorperazin

173-196

260-338

Quipazine-6N

$37^{a}$

$2560^{\mathrm{a}}$

$167^{\mathrm{a}}$

0.38

$10-13$

0.08

0.46

8

$21^{a}$

$45-53$

$104^{\mathrm{a}}$

139

508

$337^{\circ}$

$823^{\mathrm{a}}$

$232^{\mathrm{a}}$

$1960^{\mathrm{a}}$

$857^{\mathrm{a}}$

Buschman, 2007/Internal data

(a)

Buschman, 2007/Internal data

Abate et al., 2011

Azzariti et al., 2006

Lever et al., 2014

Tam and Cook, 1984

Largent et al., 1984

Weber et al., 1986

Su, 1991

Buschman, 2007/Internal data

Largent et al., 1984

Buschman, 2007/Internal data

Buschman, 2007/Internal data

\section{Su, 1991}

Buschman, 2007/Internal data

Hanner et al., 1996

Buschman, 2007/Internal data

Buschman, 2007/Internal data

Buschman, 2007/Internal data

Musacchio and Klein, 1988

Buschman, 2007/Internal data

Buschman, 2007/Internal data

Laggner et al., 2005 Buschman, 2007/Internal data

EBOV

$\mathrm{HCV}$

EBV
Akunne et al., 1997

Tam and Cook, 1984

Buschman, 2007/Internal data

Antiviral activity

\begin{tabular}{|c|c|}
\hline Virus & Referenc \\
\hline $\mathrm{HCV}$ & (Gastaminza et al., 2010) \\
\hline $\mathrm{HCV}$ & Gastaminza et al., 2010) \\
\hline
\end{tabular}

EBOV

HCoV-229E

MERS-COV

SARS-COV

SARS-CoV-2 (Jeon et al., 2020)

JCV

SARS-COV

SARS-CoV-2

CHIKV

SARS-CoV-2

SARS-CoV-2

(Johansen et al., 2015)

(de Wilde et al., 2014)

(Johansen et al., 2015)

(Brickelmaier et al., 2009)

(Dyall et al., 2014)

(Dyall et al., 2014)

(Jeon et al., 2020; Weston et al., 2020)

(Pohjala et al., 2011)

(Gordon et al., 2020)

(Gordon et al., 2020)

CHIKV

(Pohjala et al., 2011

HCV (Chockalingam et al., 2010)

(Mingorance et al., 2014)

EBOV (Johansen et al., 2015)

HCV (Chockalingam et al., 2010)

EBOV

EBOV

(Johansen et al., 2015)

(Madrid et al., 2015)

(Johansen et al., 2015)

(Gastaminza et al., 2010)

(Chockalingam et al., 2010)

SARS-CoV-2

(Gordon et al., 2020)

MERS-COV

(Nemerow and Cooper, 1984)

(Dyall et al., 2014)

HCV

ARS-CoV SARS-CoV-2 (Dyall et al., 2014; Weston et al., 2020)

EBOV

(Chockalingam et al., 2010)

(Johansen et al., 2015)

(Chockalingam et al., 2010)

(Chockalingam et al., 2010)

(Chockalingam et al., 2010)

(Mingorance et al., 2014)

(Murakami et al., 2013)

(Continued on following page) 
TABLE 1 | (Continued) Drug class.

Intended therapeutic effect

Compound

Sigma-1 receptor affinity

Antiviral activity

Sigma ligand

Rimcazole

Ki or IC50 ${ }^{\mathrm{a}}$ (nM)

References

$260^{\mathrm{a}}$
$500^{\mathrm{a}}$
820
908
$190^{\mathrm{a}}$
$151^{\mathrm{a}}$
57
$260^{\mathrm{a}}$
$17^{\mathrm{a}}$
$34-26$
$367^{\mathrm{a}}$

Lang et al., 1994
Ferris et al., 1986
Gilligan et al., 1994
Husbands et al., 1999

Antitumoral (breast cancer)

Ritanserin

Antiasthmatic

Salmeterol

Sertraline

Buschman, 2007/Internal data

Buschman, 2007/Internal data

Narita et al., 1996

HCV

Buschman, 2007/Internal data

Perregaard et al., 1995

Sigma ligand

Siramesine

Estrogen receptor modulator

Tamoxifen

Moebius et al., 1997

Buschman, 2007/Internal data

Virus

Antivital activity

References

Antitumoral (breast cancer)

\begin{tabular}{|c|c|c|}
\hline Terconazole & $159^{a}$ & Buschman, $2007 /$ Internal data \\
\hline Thiethylperazine & $528^{a}$ & Buschman, 2007/Internal data \\
\hline Thioridazine & $286^{a}$ & Buschman, $2007 /$ Internal data \\
\hline Thiothixene & $353^{a}$ & Buschman, $2007 /$ Internal data \\
\hline Toremifene & $220^{a}$ & Buschman, 2007/Internal data \\
\hline Trifluoperazine & $\begin{array}{c}15-21 \\
54 \\
125^{\mathrm{a}} \\
345^{\mathrm{a}}\end{array}$ & $\begin{array}{l}\text { Hanner et al., } 1996 \\
\text { Tam and Cook, } 1984 \\
\text { Buschman, 2007/Internal data } \\
\text { Weber et al., } 1986\end{array}$ \\
\hline Triflupromazine & $\begin{array}{l}154 \\
470^{\mathrm{a}} \\
605^{\mathrm{a}}\end{array}$ & $\begin{array}{l}\text { Tam and Cook, } 1984 \\
\text { Buschman, } 2007 / \text { Internal data } \\
\text { Weber et al., } 1986\end{array}$ \\
\hline Verapamil & $258^{\mathrm{a}}$ & Buschman, $2007 /$ Internal data \\
\hline (-)-Butaclamol & $\begin{array}{c}40 \\
95.7 \\
157 \\
183^{\mathrm{a}}\end{array}$ & $\begin{array}{l}\text { Tam and Cook, } 1984 \\
\text { Akunne et al., } 1997 \\
\text { Largent et al., } 1984 \\
\text { Weber et al., } 1986\end{array}$ \\
\hline
\end{tabular}

$\mathrm{HCV}$

(Gastaminza et al., 2010)

HCV (Chockalingam et al., 2010)

(Gastaminza et al., 2010)

SARS-CoV-2 (Gordon et al., 2020)

HCV (Mingorance et al., 2014)

(Murakami et al., 2013)

(Zurakami et al., 2013)

MERS-CoV (Dyall et al., 2014)

SARS-CoV SARS-CoV-2 (Dyall et al., 2014; Weston et al., 2020)

EBOV (Johansen et al., 2015)

MERS-CoV (Dyall et al., 2014)

SARS-CoV SARS-CoV-2 (Dyall et al., 2014; Weston et al., 2020)

Antiemetic

CHIKV

(Pohjala et al., 2011)

MERS-CoV (Dyall et al., 2014)

Antipsychotic

Antipsychotic

SARS-COV SARS-CoV-2

(P) al., 2020)

CHIKV (Pohjala et al., 2011)

EBOV (Johansen et al., 2015)

MERS-CoV (Dyall et al., 2014)

SARS-CoV (Dyall et al., 2014)

Estrogen receptor modulator

EBOV

$\mathrm{HCV}$

Johansen et al., 2013; Johansen et al., 2015)

Antitumoral (breast cancer)

MERS-COV

(Gastaminza et al., 2010)

(Dyall et al., 2014)

Antipsychotic

Antipsychotic

( \pm )-Butaclamol

$343^{\mathrm{a}}$ 
$60 \%$ of active compounds inhibiting $>85 \% \mathrm{HCV}$ infection had known affinity for Sig-1R. Most of these compounds inhibited $\mathrm{HCV}$ entry and display selective anti-HCV activity relative to vesicular stomatitis virus (VSV)-pseudotypes. In another unbiased cell-based screening, a chemical library of 281 clinically approved drugs prescribed for non-HCV applications were assayed. Twelve compounds reduced HCV infection by more than one order of magnitude without significantly reducing cell biomass (Mingorance et al., 2014). Surprisingly, all of them (chlorpromazine, clomipramine, desipramine, perphenazine, imipramine, raloxifene, tamoxifen, clomiphene, hydroxyzine, benztropine and fluoxetine) bind to Sig-1R with significant affinity (Table 1). Hydroxyzine and benztropine were selected to define the step of the replication cycle they target. Both HCV inhibitors interfered with an early step of the infection, at a step downstream viral particle attachment and internalization but previous to the establishment of persistent RNA replication and infectious virus production. Together, results reinforced the notion that compounds inhibit an early step of HCV RNA replication. The involvement of Sig-1R was not discussed in these papers, but authors noted that affinity for this molecular target was shared by a significant number of active compounds, which evoked studies addressing specifically the role of Sig-1R in HCV infection (Friesland et al., 2013).

In the third of these screening studies, 1280 compounds, many in clinical trials or approved for therapeutic use, were assayed for their ability to alleviate the $\mathrm{HCV}$-induced cytopathic effect on the engineered cell line n4mBid (Chockalingam et al., 2010). They found $>200$ hits able to increase $\mathrm{n} 4 \mathrm{mBid}$ cell viability relative to untreated cells. Of the 55 leading hits, 47 compounds inhibited one or more aspects of the HCV life cycle (entry, replication or infectious virus assembly/release) by $>40 \%$. Interestingly, significant affinity for the Sig-1R has been reported for 19 of them: amiodarone, amitriptyline, benztropine, butaclamol, cinnarizine, cyproheptadine, flunarizine, fluphenazine, ifenprodil, prochlorperazine, perphenazine, pimozide, protriptyline, quinidine, quipazine-6N, raloxifene, ritanserin, triflupromazine and trifluoperazine (Table 1). Interaction with Sig-1R has also been suggested for biperiden (Yoshida et al., 2000) and SKF-38393 has been described as allosteric modulator of the Sig-1R (Guo et al., 2013). That is, 21 out of 55 leads identified in the cell protection small-molecule screen against $\mathrm{HCV}$ were known sigma-1 binders. All of them are non-selective and typically known by their activity on molecular targets other than Sig-1R. Affinity data for Sig-1R are unknown or have not been reported for the rest of identified anti-HCV compounds and thus the possibility that Sig-1R-mediated mechanisms contribute to their effect cannot be ruled-out. Inhibition of entry and infectious virus production, assembly and release accounted for the protective effect of most known Sig-1R ligands, although some of them also inhibited HCV replication. The potential contribution of Sig-1R was not discussed.

Changes in cell death induced by avian influenza A (FLUAV) H5N1 virus in A549 lung epithelial cells were explored using RNA interference (RNAi) screening methods. These screens identified multiple genes for which knockdown altered cell viability and drugs targeting some of these genes were assayed for their potential antiviral activity. The neurological drug ifenprodil increased cell viability in vitro and markedly decreased leukocyte infiltration and lung injury, and improved survival of mice infected with H5N1 (Zhang et al., 2019), the most lethal influenza virus strain. The effect of ifenprodil was discussed in the context of its antagonism at the N-methyl-D-aspartate (NMDA) receptor as overstimulation of the NMDA receptor can trigger lung injury. In another study sharing authors with the previous one, genes and pathways differentially expressed in A549 cells upon FLUAV H5N1 virus infection were identified and some drugs were assayed as potential treatments (Huang et al., 2020). Amitriptyline increased viability of A549 cells infected with $\mathrm{H} 5 \mathrm{~N} 1$ for $48 \mathrm{~h}$ when assayed $1 \mathrm{~h}$ before infection or at $3 \mathrm{~h}$ after infection, and reduced the infiltrating cell count, decreased lung injury, improved lung edema and survival of $\mathrm{H} 5 \mathrm{~N} 1$ virus-infected mice. The involvement of Sig-1R in mediating the effects of these drugs on influenza A H5N1 virus infection was not discussed, although ifenprodil shows high affinity for Sig-1R (Hashimoto and London, 1995; Gitto et al., 2014). Amitriptyline, a non-selective antidepressant binding to multiple receptors and transporters, also binds to Sig-1R with moderate affinity (Werling et al., 2007). Note that ifenprodil and amitriptyline were previously shown to inhibit the HCV-induced cytopathic effect (Chockalingam et al., 2010).

Regarding filoviruses, a systematic in vitro screen of FDAapproved drugs was performed to identify compounds with antiviral activities against the Ebola virus (EBOV) (Madrid et al., 2015). Assays were conducted in the Vero cell line. Active compounds ( $>50 \%$ viral inhibition and $<30 \%$ cellular toxicity) at a single concentration were tested in dose-response assays. On the basis of the approved human dosing, toxicity/ tolerability and pharmacokinetic data, seven in vitro hits were selected and evaluated for their in vivo efficacy. Five of the seven (chloroquine, amiodarone, prochlorperazine, benztropine, and clomiphene) hit compounds show affinity for the Sig-1R (Table 1), although the contribution of Sig-1R-mediated mechanisms was not discussed in the paper. When administered in vivo in a mouse model, azithromycin (100 mg/kg, twice daily, i.p.), chloroquine $(90 \mathrm{mg} / \mathrm{kg}$, twice daily, i.p.), and amiodarone $(60 \mathrm{mg} / \mathrm{kg}$, twice daily, i.p.) increased survival of infected mice, but only chloroquine gave significant reproducible efficacy with this dosing regimen. Azithromycin and chloroquine were also tested in a guinea pig model of EBOV infection, but none of the tested doses increased survival. In a separate study, also testing FDA-approved drugs ( $\sim 2600$ drugs and molecular probes) in an in vitro infection assay using the type species Zaire EBOV, selective antiviral activity was found for 80 drugs spanning multiple mechanistic classes (Johansen et al., 2015). A set of 30 active compounds was prioritized. A good number of them (17 out of 30: astemizole, benztropine, bepridil, clemastine, clomiphene, clomipramine, flupentixol, fluphenazine, lomerizine, maprotiline, piperacetazine, prochlorperazine, quinacrine, sertraline, terconazole, thioridazine and toremifene) are known to display affinity for Sig-1R and most of them were indeed identified in previous studies with other viruses (Table 1). Interestingly, results in a murine EBOV infection model confirmed the 
protective ability of several drugs, notably bepridil and sertraline, which both bind Sig-1R with remarkable affinity (Table 1). Viral entry assays indicated that most of these antiviral drugs block a late stage of viral entry.

Finally, inhibition of the cytopathic effect induced by Chikungunya virus and other alphaviruses (Semliki Forest virus and Sindbis virus) was found for chlorpromazine, doxepin, methdilazine, perphenazine, thiethylperazine, thioridazine and chloroquine (Pohjala et al., 2011), all of them non-selective Sig-1R ligands that also exhibit antiviral activity against other viruses (Table 1).

\section{Pharmacology Findings Against Coronaviruses}

SARS-CoV-2 (severe acute respiratory syndrome-related CoV type 2), the causative virus of COVID-19 pandemic, belongs to the broad family of positive-sense single-stranded RNA (+ssRNA) CoV. Other $\mathrm{CoV}$ also cause illnesses ranging from common cold to more severe diseases such as Middle East respiratory syndrome (MERS). It is the seventh known CoV to infect people, after 229E, NL63, OC43, HKU1, MERS-CoV, and the original SARS-CoV (Zhu et al., 2020). Phylogenetic analyses revealed conserved evolutionary relationship between SARSCoV-2 and SARS-CoV (79.7\% nucleotide sequence identity) (Zhou et al., 2020).

In this section, data supporting the involvement of Sig-1R and therapeutic potential of Sig-1R ligands against $\mathrm{CoV}$ infection is summarized.

Chloroquine and hydroxychloroquine bind to Sig-1R (Table 1). These antimalarial drugs have shown antiviral activity against different viruses (Sperber et al., 1993; Savarino et al., 2001; Madrid et al., 2013; Ferraris et al., 2015; Wang et al., 2015). There was also evidence supporting the efficacy of chloroquine and hydroxychloroquine against other members of the Coronaviridae family before COVID-19 pandemic. Chlroroquine was described to show antiviral activity against human CoV strain OC43 (HCoV-OC43) (Keyaerts et al., 2009). $\mathrm{HCoV}-\mathrm{OC} 43$ together with $\mathrm{HCoV}-229 \mathrm{E}$ are responsible for 10 to $30 \%$ of all common colds, and infections occur mainly during the winter and early spring (Larson et al., 1980). Chloroquine inhibited $\mathrm{HCoV}-\mathrm{OC} 43$ replication in HRT-18 cells and prevented $\mathrm{HCoV}$-OC43-induced death in newborn mice when mothers were treated daily with chloroquine $(15 \mathrm{mg} / \mathrm{kg})$. On these bases, authors suggested that chloroquine might be considered as a future drug against HCoVs (Keyaerts et al., 2009). Indeed, chloroquine also inhibited the replication of SARS-CoV in vitro (Keyaerts et al., 2004) and a number of subsequent studies have confirmed its antiviral activity against SARS-CoV (de Wilde et al., 2014; Dyall et al., 2014) and recently against SARS-CoV-2 (Jeon et al., 2020; Yao et al., 2020).

Chloroquine and its hydroxy analog were by far the most popular drugs proposed initially for treatment and prophylaxis of COVID-19: 208 interventional clinical trials registered on the $\mathrm{NIH}$ site involve treatment with these drugs, alone or in combination (ClinicalTrials.gov query, 2020). In vitro, both drugs inhibit SARS-CoV-2 infection in Vero cells, but hydroxychloroquine $\left(\mathrm{EC}_{50}=0.72 \mu \mathrm{M}\right)$ is more potent than chloroquine $\left(\mathrm{EC}_{50}=5.47 \mu \mathrm{M}\right)$ (Yao et al., 2020). The benefits of this treatment have been investigated during the course of this pandemic, yet no scientific evidence supports the widespread use of these medications. In fact, results of the first clinical studies evaluating the effect of hydroxychloroquine do not support efficacy of this drug in COVID-19 patients (Geleris et al., 2020; Mitjà et al., 2020; Roustit et al., 2020). Yet, preliminary studies aroused considerable media interest, raising fears of massive and uncontrolled use of these drugs, inexpensively produced in several countries. On the other hand, serious adverse drug reactions have been reported in patients with COVID-19 receiving hydroxychloroquine. Side effects of both antimalarial drugs are well established, including serious retinopathies and cardiopathies associated with bioaccumulation of the drugs (Palmeira et al., 2020). Recently (June 15, 2020), FDA has revoked the emergency use authorization to use hydroxychloroquine and chloroquine to treat COVID-19 based on findings from a large, randomized clinical trial in hospitalized patients showing no benefit for decreasing the likelihood of death or speeding recovery (FDA communication, 2020). The mechanism of action of these aminoquinolines is thought to depend on their capacity to increase the endosomal $\mathrm{pH}$ to inhibit lysosomal enzymes. This prevents enveloped viruses from entering and releasing their genetic material into the host cells (Tripathy et al., 2020). Binding to a ganglioside-binding domain at the N-terminal domain of the SARS-CoV-2 S protein has also been suggested as a mechanism of chloroquine and hydroxychloroquine to inhibit attachment of the virus to lipid rafts and contact with the ACE-2 receptor for entry (Fantini et al., 2020). The only reference to Sig-1R comes from an unrelated study describing protection by chloroquine against glutamate-induced cell death through a Sig-1R-mediated mechanism (Hirata et al., 2011). The eventual contribution of Sig- $1 \mathrm{R}$ to the antiviral effects of chloroquine and hydroxychloroquine is just starting to be recognized (Gordon et al., 2020; Mirabelli et al., 2020), but they are non-selective Sig-1R ligands and their affinities for this molecular target are suboptimal.

The antiarrhythmic amiodarone, a non-selective but high affinity sigma-1 ligand, was reported to inhibit the spreading in vitro of SARS-CoV in Vero cells (Stadler et al., 2008). Amiodarone reduced the virus titer in a concentrationdependent manner, at concentrations at which it has no effect on cell viability. Direct interaction with the SARS-CoV or impairment of virus entry did not account for its antiviral activity, but amiodarone interfered with the SARS-CoV life cycle after delivery of its genome in the cytosol. As a cationic amphiphilic drug, amiodarone (and its main metabolite MDEA) accumulates into late endosomes/lysosomes and reduces their lumenal acidity, precluding acidic cleavage of viral proteins and interfering with the endocytic pathway (Salata et al., 2015). However, amiodarone displayed antiviral activity even when SARS-CoV has delivered its genome into the cytoplasm, thus involving additional mechanisms at a 
post-endosomal level (Stadler et al., 2008). The contribution (or not) of sigma-1-mediated mechanisms to the antiviral activity of amiodarone was not discussed in the publications. Amiodarone was also shown to inhibit the HCV-induced cytopathic effect on the engineered cell line n4mBid (Chockalingam et al., 2010), HCV entry and assembly steps in Huh-7.5.1 cells (Cheng et al., 2013), and EBOV cell entry in a variety of cultured cell lines (Gehring et al., 2014; Salata et al., 2015; Dyall et al., 2018). Despite promising in vitro results, amiodarone failed to protect guinea pigs from a lethal dose of EBOV (Dyall et al., 2018). In the clinical setting, in December 2014, approximately 80 patients in Ebola treatment units in Freetown, Sierra Leone, received amiodarone as a compassionate therapy at doses up to $30 \mathrm{mg} / \mathrm{kg}$ per day (ClinicalTrials.gov Identifier NCT02307591, 2014). A decrease in case fatality rate was reported when compared with local historical data. Unfortunately, the study was not a formal clinical trial, and the statistical significance of this result is not known (Turone, 2014; Gupta-Wright et al., 2015). Recently, the case of a patient affected by COVID-19-related respiratory failure who recovered after only supportive measures and off-label short therapy with amiodarone (starting on the second day from admission and lasting 5 days; administered on day 1 as a $15 \mathrm{mg} / \mathrm{kg} / 24 \mathrm{~h}$ intravenous infusion, followed by oral administration of $400 \mathrm{mg}$ twice daily) has been reported (Castaldo et al., 2020). Accordingly, amiodarone, widely prescribed to treat both ventricular and supraventricular arrhythmias, has been proposed as a possible therapy (alone or as part of a combination regimen) to prevent SARS-CoV-2 infection rather than to treat symptomatic or severe COVID-19 patients (Aimo et al., 2020; Sanchis-Gomar et al., 2020).

A set of 348 FDA-approved drugs was screened in cell cultures infected with MERS-CoV (de Wilde et al., 2014). Four compounds (chloroquine, chlorpromazine, loperamide, and lopinavir) inhibited MERS-CoV replication in the low-micromolar range $\left(\mathrm{IC}_{50 \mathrm{~s}} 3\right.$ to $8 \mu \mathrm{M}$ ). These compounds also inhibited the replication of SARS-CoV and HCoV-229E. Interestingly, chloroquine but also chlorpromazine and loperamide bind to Sig-1R (Table 1). Time-of-addition experiments suggested that chloroquine, chlorpromazine and loperamide inhibit an early step in the replicative cycle whereas lopinavir inhibits a post-entry step. This finding is congruent with previous findings showing that Sig-1R regulates early stages of HCV RNA replication (Friesland et al., 2013).

In another study, a library of 290 compounds with FDA approval or in advanced clinical development was screened for antiviral activity against MERS-CoV and SARS-CoV (Dyall et al., 2014). Twenty seven compounds displayed in vitro activity against both MERS-CoV and SARS-CoV. Among the 27 active compounds, at least 19 bind with significant affinity to Sig-1R (chloroquine, hydroxychloroquine, mefloquine, amodiaquine, tamoxifen, toremifene, terconazole, cycloheximide, benztropine, fluspirilene, thiothixene, fluphenazine, promethazine, astemizole, chlorphenoxamine, chlorpromazine, thiethylperazine, triflupromazine and clomipramine) (Table 1), though their antiviral activity was not discussed to be related to Sig-1R. Recently, authors prioritized 20 drugs from this previous screening and found that 17 of the 20 tested drugs that inhibited SARS-CoV and MERS-CoV also inhibited the cytopathic effect of SARS-CoV-2 on Vero E6 cells, with similar $\mathrm{IC}_{50}$ values and at non-cytotoxic concentrations (Weston et al., 2020). All (amodiaquine, benztropine, chloroquine, chlorpromazine, clomipramine, fluphenazine, fluspirilene, hydroxychloroquine, mefloquine, promethazine, tamoxifen, terconazole, thiethylperazine and toremifene) but two are known to bind Sig-1R (Table 1). Two of them, chloroquine and chlorpromazine, were evaluated in vivo using a mouse-adapted SARS-CoV model. Drug treatments did not inhibit virus replication in lungs, but did protect mice from clinical disease (Weston et al., 2020). Note that repurposing not only of chloroquine but also of the antipsychotic chlorpromazine has been proposed to treat COVID-19 (Nobile et al., 2020; Plaze et al., 2020).

In a recent repositioning study, 48 FDA-approved drugs, including 35 drugs pre-selected by their activity against SARS$\mathrm{CoV}$ snd 13 drugs recommended from infectious diseases specialists, were assayed for their antiviral activity against SARS-CoV-2 in Vero cells (Jeon et al., 2020). Infected cells were analyzed by immunofluorescence using an antibody against the viral $\mathrm{N}$ protein of SARS-CoV-2. Among the 48 drugs evaluated, 24 showed potential anti-SARS-CoV-2 activity, with $\mathrm{IC}_{50}$ values between 0.1 and $10 \mu \mathrm{M}$. Three of them, loperamide, mefloquine and amodiaquine, in addition to chloroquine, are known to bind Sig-1R (Table 1). All of them were previously shown to be effective against other $\mathrm{CoV}$, including MERS-CoV and SARS-CoV (Dyall et al., 2014).

In a recent paper, targeting Sig-1R was highlighted based on findings of a SARS-CoV-2 protein interaction map and pharmacological data (Gordon et al., 2020). Screening a subset of drugs identified two sets of pharmacological agents effectively reducing SARS-CoV-2 infectivity in Vero-6 cells: inhibitors of mRNA translation and predicted regulators of the sigma- 1 and sigma-2 receptors. Non-selective Sig-1R ligands including haloperidol, PB28, PD-144418 and hydroxychloroquine, and subsequently clemastine, cloperastine, progesterone and siramesine (Table 1) were found to exert antiviral effects. Hydroxychloroquine was among the less potent antiviral of the assayed Sig-1R ligands, which correlated with its lower affinity for this molecular target. Authors discussed the involvement of sigma receptors. They noted that these molecules are also active against other receptors, but the only shared among all of them are the sigma receptors. For instance, the antipsychotic haloperidol inhibits the dopamine D2 and histamine $\mathrm{H} 1$ receptors, while clemastine and cloperastine are themselves antihistamines, but all three molecules are Sig-1R ligands and exert antiviral activity. In contrast, the antipsychotic olanzapine, which also inhibits $\mathrm{H} 1$ and $\mathrm{D} 2$ receptors, has no significant Sig-1R activity and is not antiviral. Authors also noted that the widely used antitussive dextromethorphan exerted proviral activity and stated that its use should merit caution and further study in the context of COVID-19. Dextromethorphan but also carbetapentane, another commonly used antitussive (Brown et al., 2004), the narcotic analgesic pentazocine (particularly its active (+)-pentazocine enantiomer) (Tam and Cook, 1984) and some antidepressants 
(Narita et al., 1996), among some other marketed compounds, are considered prototype Sig-1R agonists/positive modulators. Thus, should caution be extended to the use of other potential, although non-selective Sig-1R agonists? In this way, cocaine is a nonselective Sig-1R agonist and exposure to cocaine has been shown to enhance HIV infection by activating Sig-1R (Roth et al., 2005). Cocaine use/abuse could thus be a risk factor but, to my knowledge, the effect of cocaine on $\mathrm{CoV}$ infections has not been investigated.

Finally, in a recent publication, quantitative high-content morphological profiling coupled with an AI-based machine learning strategy was applied to identify efficacious single agents against SARS-CoV-2 (Mirabelli et al., 2020). This assay detected multiple antiviral mechanisms of action, including inhibition of viral entry, propagation, and modulation of host cellular responses. Viral growth kinetics were assayed at a multiplicity of infection of 0.2 in Huh-7 cells, with peak viral titers at $48 \mathrm{~h}$ post infection. From a library of 1,441 FDAapproved compounds and clinical candidates, 15 doseresponsive compounds with antiviral potency below $1 \mu \mathrm{M}$ and devoid of cytotoxicity were identified. Three of them, amiodarone, verapamil and E-52862 (S1RA) were known to bind Sig-1R (Table 1). Interestingly, E-52862 (S1RA) is a selective Sig-1R antagonist (Romero et al., 2012). It exerted potent activity against SARS-CoV-2 in Huh-7 cells $\left(\mathrm{IC}_{50}=\right.$ $222 \mathrm{nM})$ and iPSC-derived alveolar epithelial type 2 cells (iAEC2s) $\left(\mathrm{IC}_{50}=1 \mu \mathrm{M}\right)$, with limited cell toxicity $\left(\mathrm{CC}_{50}>\right.$ $5000 \mathrm{nM}$ ). E-52862 (S1RA) depleted infected cells and induced cellular changes suggestive of a host-modulation mechanism, which led to suggest that the activity of S1RA is dependent on host cell mechanisms (presumably active in Huh-7 and iAEC2s cells but not in Vero- 6 cells, which are highly permissive to viral growth) and, promisingly, that human cells may be more responsive to this compound. This (and differences in other experimental conditions) could explain way E-52862 was devoid of activity when assayed in the Vero E6 cell line (Gordon et al., 2020).

\section{MECHANISM OF ACTION}

\section{Sigma-1 Receptor and Viral Entry}

Inhibition of viral entry has been reported for non-selective sigma-1 ligands in a number of studies (Chockalingam et al., 2010; Gastaminza et al., 2010; Cheng et al., 2013; Johansen et al., 2015; Dyall et al., 2018), but not in others (Nemerow and Cooper, 1984; Mingorance et al., 2014; Stadler et al., 2008; de Wilde et al., 2014; Gordon et al., 2020). Thus, it is unclear whether prevention of viral particle attachment or internalization accounts for Sig1R-mediated antiviral effect of such drugs.

Inhibition of HCV entry into Huh-7 human hepatoma cells by sigma-1 ligands was demonstrated in pharmacology studies (Gastaminza et al., 2010), but downregulation of Sig-1R in Huh-7 cells did not affect HCV entry (Friesland et al., 2013). This might suggest that the deficiency of the modulatory sigma-1 protein (as in the case of gene silencing approaches) does not mimic the pharmacological inhibitory effect on viral entry elicited by an antagonist acting at the Sig-1R. Accordingly, absence of the regulatory mechanism in Sig-1R deficient cells would not be equivalent to the inhibitory effect promoted by a Sig-1R ligand on the target protein with which Sig-1R is interacting. This is possible due to the chaperone nature of the Sig-1R, which exerts its action through physical protein-protein interactions (Su et al., 2010; Pabba, 2013).

Sig-1R normally resides at the ER, typically at the MAM, but when cells undergo stress (as expected following viral infection) the Sig-1R translocates to the peripheral ER network and plasma membrane to regulate a variety of cell surface proteins (Su et al., 2010), which might account for ligand-operated, Sig-1Rmediated modulation of virus attachment or entry (Figure 1). In this way, Sig-1R associates to heavy chain binding immunoglobulin protein $(\mathrm{BiP}$, also known as glucose regulating protein 78, GRP78; or heat shock $70 \mathrm{kDa}$ protein 5 , HSPA5) in the ER (Hayashi and Su, 2007). BiP also translocates upon cell stress from the ER to the cell surface, exposes multiple domains on the cell surface and assumes new functions (Zhang et al., 2010), including virus recognition by its substrate-binding domain and facilitation of entry of several viruses, including $\mathrm{CoV}$ (Chu et al., 2018) (Figure 1). The capacity of BiP to facilitate surface attachment and viral entry likely depends on its binding to surface $S$ (spike) viral proteins, as demonstrated for MERS$\mathrm{CoV}$ and bat CoV-HKU9, and predicted for SARS-CoV-2 (Ibrahim et al., 2020). Sig-1R is engaged in protein trafficking from the ER to the plasma membrane, binds to $\mathrm{BiP}$ and, like $\mathrm{BiP}$, it trasnlocates to the cell surface upon ER stress (Hayashi, 2019), but the involvement of Sig-1R in the export of $\mathrm{BiP}$ to the plasma membrane has not been investigated. Sig-1R antagonists inhibit Sig-1R-BiP dissociation at the ER (Hayashi and Su, 2007; Hayashi, 2019) and this might prevent BiP trafficking, surface expression and ultimately $\mathrm{CoV}$ attachment via BiP. Unlike Sig$1 \mathrm{R}, \mathrm{BiP}$ is described as a non-membrane-bound ER lumenal chaperone. Thus, the interaction with Sig-1R could allow BiP stabilization/anchoring to the plasma membrane, although putative transmembrane domains have been identified allowing its potential, autonomous cell surface relocalization (Zhang et al., 2010). Yet, no direct interaction of Sig-1R with $\mathrm{BiP}$ has been specifically described at the plasma membrane. Similarly, no direct interaction with other host membrane proteins involved in viral attachment/entry (e.g., ACE2 or TMPRSS2) or with structural viral envelope proteins has been described substantiating Sig-1R-dependent modulation of viral entry. Alternatively, as discussed later, Sig-1R might regulate early stages of RNA replication and host cell response but not viral entry, whereas structural features shared by a number of sigma-1 ligands, independent on their binding to Sig-1R, might account for viral entry inhibition.

\section{Sigma-1 Receptor Ligands as Lysosomotropic Agents?}

The endocytic pathway (receptor-dependent endocytosis) is a basic mechanism for entry of CoV, including SARS-CoV, MERS$\mathrm{CoV}$ and SARS-CoV-2, into host cells (Glebov, 2020; Yang and Shen, 2020). Binding of the spike (S) protein of SARS-CoV-2 to its receptor exposes its cleavage sites to cellular proteases, 


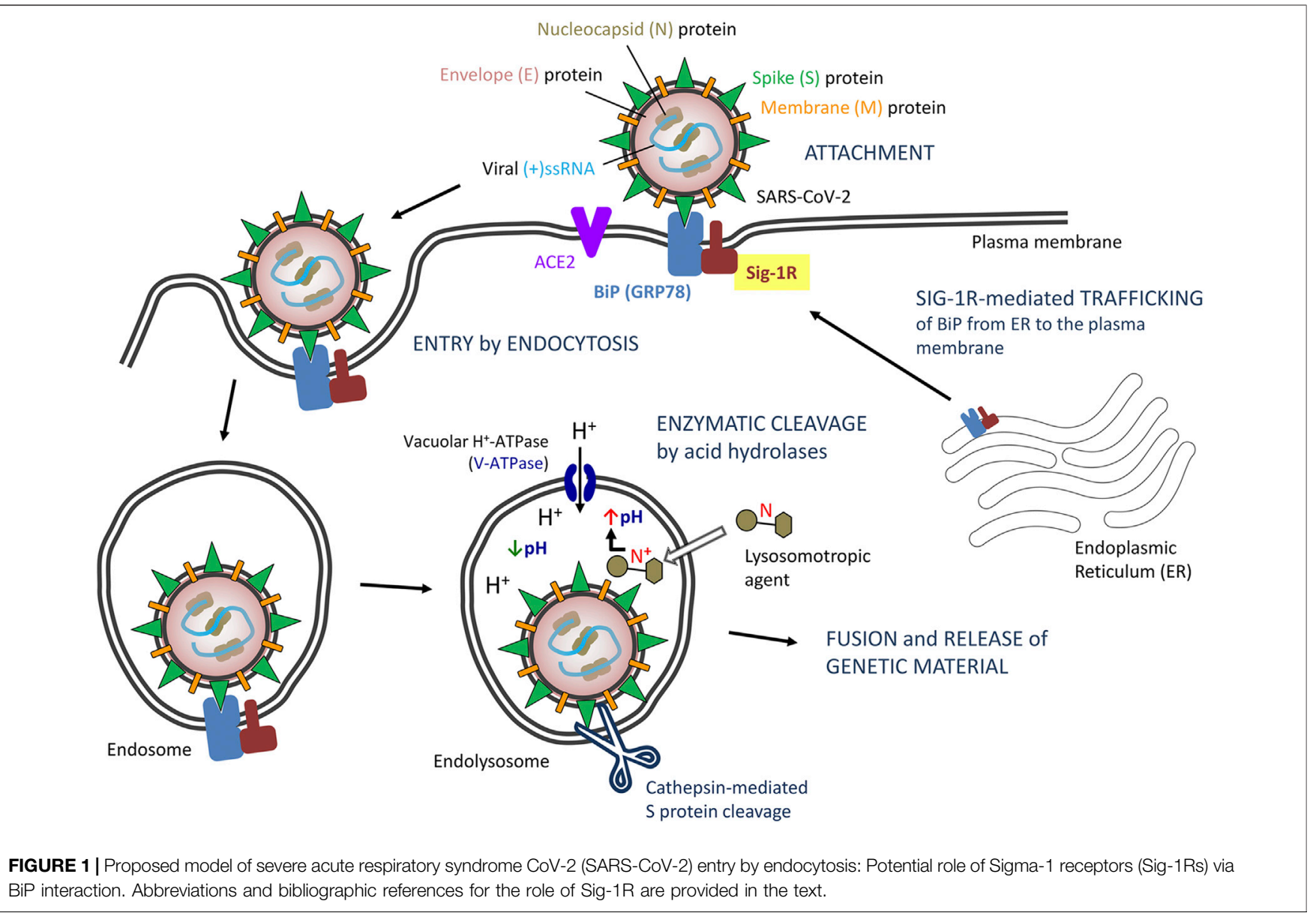

including endosomal acid proteases involved in endocytic processing (Millet and Whittaker, 2015; Pillay, 2020). In particular, endosomal cathepsin-mediated S protein cleavage is considered a critical step for $\mathrm{CoV}$ entry and initiation of infection (Millet and Whittaker, 2015; Glebov, 2020; Wędrowska et al., 2020; Yang and Shen, 2020).

Endosomes and maturation of endosomes into a lysosome is featured by their acidic internal $\mathrm{pH}$, which is required for acid proteases and critical for SARS-CoV-2 processing and internalization (Wedrowska et al., 2020). The plasma and lysosomal membranes are highly permeable to the unionized form of weak bases but are essentially impervious to the protonated form of the bases (Marceau et al., 2012; Homolak and Kodvanj, 2020). Accordingly, weak bases, unionized in the cytoplasm, can cross the lysosomal membrane and enter the lysosome. Once in the lysosome, they are rapidly protonated since the lysosomal $\mathrm{pH}$ is considerably lower than the cytosolic $\mathrm{pH}$, and become trapped inside lysosomes. This results in intralysosomal accumulation (ion trapping) of the drug and increased lysosomal $\mathrm{pH}$ (i.e., neutralization of lysosomal $\mathrm{pH}$ ) sufficient to block most lysosomal enzymatic activity. If the concentration of the protonated base inside the lysosome is high enough, water enter the lysosome osmotically and the lysosomes swell to form large vacuoles (i.e., lysosomal vacuolation), with the consequent loss of lysosomal function (Aki et al., 2012).
Some drugs recognized as antiviral agents are lipophilic amines/weak bases that accumulate and preclude acidification of lysosomes, thus inhibiting virus internalization and postinternalization trafficking to the site of replication (Sieczkarski and Whittaker, 2002; Kaufmann and Krise, 2007; Mercer et al., 2010). Such lysosomotropism is shared by some lipophilic amines and cationic amphiphilic drugs (Kaufmann and Krise, 2007), including chloroquine and other anti-malarial drugs (Homolak and Kodvanj, 2020). Indeed, lysosome targeting agents are considered a potential therapy for COVID-19 (Homolak and Kodvanj, 2020). However, the effectiveness of this mechanism of action to control viral infections is hampered by its low specificity, cell compensation mechanisms to lower/restore intralysosomal $\mathrm{pH}$ and egress entrapped amines from lysosomes (Goldman et al., 2009), and the need for high drug dosage to allow substantial drug accumulation and alkalinization inside lysosomes, which also raises safety concerns.

A variety of marketed drugs fit within general physicochemical properties of lysosomotropic agents. Essentially, drugs with a ClogP $>2$ and $\mathrm{pKa}$ between 6.5 and 11 can accumulate into lysosomes (Nadanaciva et al., 2011), although other physicochemical features also affect lysosomotropism (Kaufmann and Krise, 2007). Pharmacophore models for sigma-1 ligands (both putative agonists and antagonists) specify a positive ionizable group (i.e., a basic nitrogen, usually 
secondary or tertiary amine) flanked by hydrophobic regions (Pascual et al., 2019), which is coherent with potential lysosomotropism (Figure 1). This might have two implications. First, lysosomal sequestration might represent a barrier for a Sig-1R drug in reaching its intended target and would reduce its access to other cellular compartments (eg, ER, MAM or nuclear membranes) where Sig-1R is located for its antiviral effect to occur. Second, lysosomal trapping would result in unspecific, Sig-1R-independent defective acidification of lysosomes, and this off-target effect might be an added value for such drugs. It is clear that Sig-1R-mediated modulation of both viral replication and virus-induced ER-stress response might dependent on targetspecific binding of ligands to Sig-1Rs in cellular compartments other than lysosomes, but it is presently unclear whether the pharmacophore-related, potential lysosomotropism of Sig-1R ligands actually hinders or contributes (and to what extent) to the activity reported for some Sig-1R ligands in antiviral drug screens.

\section{Sigma-1 Receptor Regulates Early Steps of Viral RNA Replication}

In this section, evidence gained through gene silencing approaches are discussed. The antiviral activity exerted by numerous sigma-1 ligands in drug repurposing in vitro screens was not invariably unnoticed. Following the trail of pharmacological findings described before (Gastaminza et al., 2010), the role played by Sig-1R in HCV infection was investigated. RNAi though lentivirus-delivered short hairpin RNA (shRNA) targeting Sig-1R mRNA was used to downregulate Sig-1R expression in Huh-7 human hepatoma cells (Friesland et al., 2013). Four different shRNAs caused Sig-1R protein silencing with different magnitudes as compared with control cells transduced with an irrelevant shRNA. Control and silenced cells were inoculated with infectious HCV virions and infection efficiency was monitored by measuring the production of intracellular and extracellular progeny infectious virus as well as intracellular HCV RNA. Downregulation of Sig-1R expression in Huh-7 cells caused a proportional decrease in susceptibility to $\mathrm{HCV}$ infection, as shown by reduced HCV RNA accumulation and intra- and extracellular infectivity in single-cycle infection experiments. That is, progeny virus production was proportional to cellular Sig-1R levels at 24 and $48 \mathrm{~h}$ postinfection. Experiments were also conducted to explore the underlying mechanisms and revealed that Sig-1R downregulation did not affect HCV entry and that its expression levels were not limiting for primary translation of viral RNA genome, persistent HCV RNA replication (steady-state HCV RNA replication) or particle assembly and secretion. However, sigma-1 expression was rate limiting for launching HCV RNA replication. The reduced accumulation of HCV RNA in Sig-1R-deficient cells in single-cycle infection experiments was due to a defect in the establishment of HCV RNA replication, downstream of primary translation. Accordingly, Sig-1R expression is rate limiting for RNA replication early after primary translation but it is dispensable once the viral replication machinery has been established and replication reaches steady-state levels, as observed in persistently infected cells. Another remarkable result in the study by Friesland et al. (2013) is that Sig-1R expression in Huh-7 cells was rate limiting for $\mathrm{HCV}$ infection but not for infection with negative-sense single-stranded RNA viruses such as influenza A virus (A/ WSN/33) or VSV (Friesland et al., 2013). Accordingly, evidence on the role played in viral replication by host Sig-1R in cultured hepatoma cells (not the primary cell target of SARS$\mathrm{CoV}-2$ ) infected with $\mathrm{HCV}$ ( $\mathrm{a}+\mathrm{ssRNA}$ virus, but not SARS-CoV2 ) in no case imply proven mechanistic correlates against SARSCoV-2 on its natural target cells.

Overall, data from Sig-1R deficient cells indicate that Sig-1R is a host cellular factor recruited for HCV infection, downstream entry, delivery and primary translation of viral RNA genome that regulates early stages of HCV RNA replication (Friesland et al., 2013). This is consistent with pharmacology findings whereby Sig-1R ligands (unrecognized as active ligands at Sig-1R in most studies) where found to inhibit early steps of the replicative cycle, after viral particle attachment, internalization and delivery of its genome to the cytosol (Nemerow and Cooper, 1984; Mingorance et al., 2014; Stadler et al., 2008; de Wilde et al., 2014; Gordon et al., 2020).

\section{Sigma-1 Receptor Colocalizes and Interacts with Non-Structural Proteins of the Viral Replicase/Transcriptase Complex} In this section, evidence gained from colocalization and interactome map studies are discussed. Sig-1R was found to colocalize with NS proteins of the HCV replication complex (Friesland et al., 2013). Cells were processed for double immunostaining with antibodies directed against components of the viral replicase (NS3, NS4B and NS5A) and against Sig-1Rs. In mock-infected Huh-7 cells, Sig-1R immunofluorescence revealed a predominant discrete cytoplasmic punctae localization that was juxtaposed to mitochondria as well as diffuse cytoplasmic pattern that colocalized with ER, the characteristic cellular distribution of Sig-1R in normal resting, unstressed cells (Su et al., 2010). During infection, the intracellular pattern of Sig-1R distribution changed: more that $70 \%$ of the infected cells displayed a diffuse perinuclear pattern $48 \mathrm{~h}$ postinfection. Interestingly, Sig-1R co-localized with viral NS3, NS4B and NS5A replicase components at perinuclear regions during early steps of viral infection. Later during infection $(72 \mathrm{~h})$, more than $60 \%$ of the infected cells displayed discrete cytoplasmic punctae that did not clearly colocalize with the bulk NS protein perinuclear signal, suggesting that a fraction of Sig-1R recovers the original pattern and that perinuclear colocalization of Sig-1R with viral replicase NS proteins observed at $48 \mathrm{~h}$ is transient. Overall, these results suggest that Sig-1R is recruited to perinuclear areas of the ER where NS proteins accumulate at early stages of viral infection to regulate the initiation of HCV RNA replication. Most Sig-1R and NS3 and NS5A were associated with detergent-resistant, cholesterol- and sphingolipid-rich intracellular membranes, further suggesting that Sig-1R and components of the $\mathrm{HCV}$ replicase target similar ER membrane environments, where Sig-1R likely exerts its proviral functions. Notably, such transient sigma-1 
relocalization has been described during ER stress and proposed to contribute to the cellular response to stress (Hayashi and $\mathrm{Su}$, 2007), suggesting that the virus takes advantage of host stressrelated proteins to deploy a favorable cellular program. Cellular stress pathways induced by HCV infection to promote both viral replication and survival of the infected cell as well as the proviral role of Sig-1R in HCV infection have been reviewed (Vasallo and Gastaminza, 2015) and will not be reviewed further here.

Recently, a SARS-CoV-2 protein interaction map reveled a physical interaction with Sig-1R (Gordon et al., 2020). Authors cloned, tagged and expressed 26 of the 29 SARS-CoV-2 proteins and identified SARS-CoV-2-human protein-protein interactions using affinity-purification mass spectrometry. Approximately $40 \%$ of SARS-CoV-2 interacting proteins were associated with endomembrane compartments or vesicle trafficking pathways. In particular, the viral NS protein Nsp6 was specifically found to interact with Sig-1R. The SARS-CoV-2 genome encodes as many as 14 open reading frames (Orfs) (Masters, 2006; Chan et al., 2020; Gordon et al., 2020; Wu et al., 2020). The Orf1a/Orf1ab at the $5^{\prime}$ two-thirds of the genome encodes precursor polyproteins, which are auto-proteolytically processed into 16 NS proteins (Nsp1-16) that form the replicase/transcriptase complex. At the 3 ' end of the viral genome, as many as 13 additional Orfs are expressed from sub-genomic mRNAs encoding Spike (S), Envelope (E), Membrane (M) and Nucleocapsid (N) structural proteins and putative accessory proteins. The viral replication machinery is thought to localize in ER membranes thanks to Nsp3, Nsp4 and Nsp6. Nsp6 forms complexes with Nsp3 and $\mathrm{Nsp} 4$ to anchor the viral replicase/transcriptase complex to ER membranes (Oostra et al., 2008; Alsaadi and Jones, 2019). All three replicase proteins contain transmembrane-spanning sequences important for assembly of the viral replicase/ transcriptase complex to the ER membrane (Oostra et al., 2008). Nsp6 was shown to contain seven hydrophobic domains but six transmembrane domains, with its amino and carboxy termini exposed in the cytoplasm, and a conserved hydrophobic domain in the C-terminal cytosolic tail (Oostra et al., 2008; Baliji et al., 2009). Two nsp6 products of approximately 23 and $25 \mathrm{kDa}$ were identified by Western immunoblotting, although the reason for the existence of multiple forms of nsp6 is currently unknown (Baliji et al., 2009). In addition to its role in anchoring the replicase complex to ER membranes, Nsp6 has been found to induce double-membrane vesicles and autophagosome formation (Cottam et al., 2011).

Positive-strand RNA viruses, including HCV and SARS-CoV, sequester host cell ER membranes to assemble viral replication. A network of modified perinuclear rough ER that integrates convoluted membranes, interconnected double-membrane vesicles and vesicle packets has been described (Gosert et al., 2002; Knoops et al., 2008; Sola et al., 2015). The viral replicase subunits were most abundantly located in convoluted ER membranes, RNA replication (double-stranded RNA) localized in double-membrane vesicles, and vesicle packets appeared to result from the merge of double-membrane vesicles and develop into large cytoplasmic vacuoles containing (budding) virus particles. Ultimately, replication of the $\mathrm{CoV}$ genome requires continuous RNA synthesis (Sola et al., 2015) and the reticulovesicular network provides a structural and functional continuum that connects ER membrane structures involved in RNA synthesis to sites at which the assembly of new virions occurs (Knoops et al., 2008). According to previous studies, Sig$1 \mathrm{R}$ is required at early stages of replication but not for steady-state HCV RNA replication or infectious particle assembly and secretion (Friesland et al., 2013). Thus, internalization, delivery and primary translation of the viral RNA genome would precede the recruitment of Sig-1R, which complexes with newly synthesized viral replicase proteins at initial stages before the reticulovesicular network continuum has fully developed in persistent infections. Early and transient colocalization of Sig1R with HCV replicase proteins (Friesland et al., 2013) and interaction of Sig-1R with Nsp6 SARS-CoV-2 replicase protein (Gordon et al., 2020) support this hypothesis. The functional purpose of this interaction is unknown. A prompt assumption is that Sig-1R might assist insertion of the viral replication machinery to ER (convoluted) membranes, as anchoring of the replicase/transcriptase complex to the ER membrane is the proposed role of its partner Nsp6. However, it might also allow proper folding or membrane orientation of nascent viral proteins to assist multiprotein assembly of the functional replicase/ transcriptase complex, promote early ER remodeling and trafficking through the reticulovesicular network, and/or regulate ER-mitochondrion signaling and ER-nucleus crosstalk to couple host cell bioenergetics and biosynthetic machinery to early viral demands. All these functions are coherent with the role played by this resident ER chaperone/scaffolding and dynamic pluripotent modulator protein, involved in inter-organelle signaling, bioenergetics and cellular stress responses (Hayashi and Su, 2007; Su et al., 2010; Vollrath et al., 2014; Hayashi, 2019; Delprat et al., 2020).

\section{A Role for Sigma-1 Receptor in Coronavirus-Induced Host Cellular Stress?}

$\mathrm{CoV}$ infection of cultured cells causes ER stress and induces the unfolded protein response (UPR), the ER-specific stress response, and their downstream signals (Fung and Liu, 2014; Fung et al., 2014a). ER stress and UPR have been particularly involved in SARS-CoV-2 infection (Sureda et al., 2020) and combination therapies targeting COVID-19-mediated ER stress have been recently proposed (Banerjee et al., 2020). UPR aims to restore ER homeostasis and cell survival by global translation shutdown and increasing the ER folding capacity. The UPR signaling starts with the unfolded proteins activating three ER stress transducers: double-stranded RNA-activated protein kinase (PKR)-like ER protein kinase (PERK), activating transcriptional factor-6 (ATF6), or inositol-requiring enzyme (IRE1). Reversible dissociation from the ER lumenal chaperone BiP (also known as GRP78 or HSPA5) and interactions with other ER cochaperones regulates the activation/deactivation dynamics of UPR transducers. BiP seems to be the direct ER stress sensor as it becomes activated by misfolded proteins. In unstressed cells, $\mathrm{BiP}$ binds to the ER lumenal domains of ER stress transducers and maintains them in an inactivated state (Figure 2). During ER 


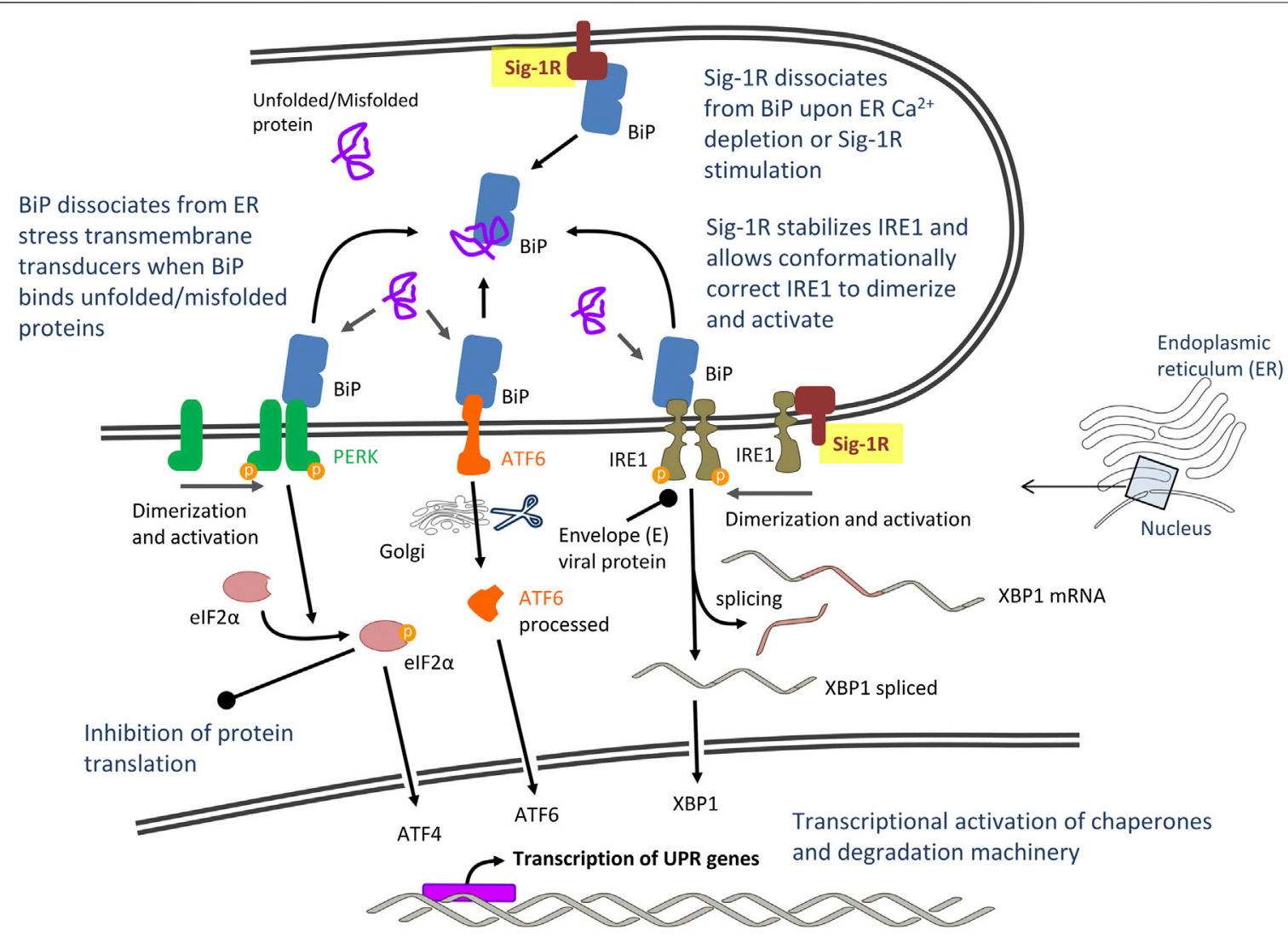

FIGURE 2 | Proposed model of severe acute respiratory syndrome CoV-2 (SARS-CoV-2)-mediated unfolded protein response (UPR) signaling: Potential role of Sigma-1 receptors (Sig-1Rs) via interaction with master UPR regulators. Abbreviations and bibliographic references for the role of Sig-1R are provided in the text.

stress, BiP preferentially binds to unfolded and misfolded proteins and dissociates from transmembrane transducers, facilitating their activation (Bertolotti et al., 2000; Kopp et al., 2019). Once activated, UPR transducers transmit the signal to the cytosol and the nucleus, and the cell responds by lowering the protein synthesis and increasing the ER folding capacity. The PERK/eIF2 $\alpha$ (eukaryotic initiation factor 2a)/ATF4 pathway rapidly attenuates protein translation, whereas the ATF6 and the IRE1a/XBP1 (transcription factor X-box binding protein-1) cascades transcriptionally upregulate ER chaperone genes that promote proper folding (Figure 2). Accumulated unfolded proteins are either correctly refolded or unsuccessfully refolded and cleared via the ER associated degradation complex (ERAD) ubiquitin-proteasome pathway or via autophagy. However, under prolonged ER stress, UPR can also induce apoptotic cell death if homeostasis cannot be re-established and accumulation of misfolded protein becomes toxic. Apoptosis is triggered potentially via UPR-mediated and $\mathrm{Ca}^{2+}$-mediated caspase activation pathways and recruitment of mitochondria (Kim et al., 2006; Fung and Liu, 2014; Karagöz et al., 2019). Indeed, $\mathrm{Ca}^{2+}$ homeostasis plays a major role in ER stress and UPRmediated apoptosis induction. Depletion of ER $\mathrm{Ca}^{2+}$ stores has detrimental effects on ER-resident $\mathrm{Ca}^{2+}$-dependent chaperones and protein folding, and undue $\mathrm{Ca}^{2+}$ transfer from ER to mitochondria at MAM (i.e., mitochondrial $\mathrm{Ca}^{2+}$ overload) leads to mitochondrial reactive oxygen species (ROS) production/oxidative stress and cytochrome $\mathrm{C}$ release (Carreras-Sureda et al., 2018). Finally, autophagy may also be activated under ER stress (ER stress-mediated autophagy) by pathways sharing common upstream signaling with UPR, including PERK, IRE1, ATF6 and $\mathrm{Ca}^{2+}$ (Song et al., 2017). Autophagy is characterized by the engulfment of cytoplasmic components in double-membrane-bound structures that are then delivered to lysosomes/vacuoles for degradation. Autophagosomes include worn-out proteins, protein aggregates and damaged organelles (Lee et al., 2015; Rashid et al., 2015; Song et al., 2017).

The burst of protein synthesis overloading the ER folding capacity, extensive rearrangement of the ER membrane during viral replication and viral proteins such as S (Siu et al., 2014) and 3a accessory (Minakshi et al., 2009) proteins of CoV cause ER stress, but viruses have evolved mechanisms to manage UPR signaling and create an environment favorable for its replication (Fung and Liu, 2014). Operative but hijacked UPR, with selective translational and transcriptional reprogramming but reduced susceptibility to cell death would contribute to host cell survival and sustain viral replication. Accordingly, CoV activate UPR transducers but induce minimal downstream induction of some UPR target genes. This favors a sustained shutdown of the synthesis of host cell proteins while the 
translation of viral proteins escalates (Bechill et al., 2008). Also favoring viral infection, the envelope E protein of SARS-CoV has been shown to neutralize the IRE1a/XBP1 pathway of UPR and inhibit apoptosis (DeDiego et al., 2011). Note that apoptosis is a fatal fate for the infected cell, but it protects the host by limiting virus production and dissemination. However, not all the evidence has the same directionality and some findings support that ER stress, UPR and autophagy induction are innate responses in cell host's struggle with CoV. For instance, infection with the alphaCoV transmissible gastroenteritis virus (TGEV) activated all three UPR pathways (PERK, ATF6 and IRE1), but activation of the PERK/eIF2 $\alpha$ axis inhibited TGEV replication through overall attenuation of protein translation (Xue et al., 2018). The PERK pathway was also activated in cells expressing the $3 \mathrm{a}$ accessory protein of SARS-CoV, a protein that is pro-apoptotic (Minakshi et al., 2009). Other studies point to a mix of positive and negative effects on viral replication. For instance, IRE1 RNase activity was reported to be unfavorable to viral replication whereas IRE1 kinase activity enhanced it (Su et al., 2017).

What about Sig-1R? ER stress/UPR induces Sig-1R expression through the PERK/eIF2a/ATF4 pathway (ATF4 binds to the 5' flanking region of Sig-1R gene to upregulate its transcription) (Mitsuda et al., 2011). In turn, Sig-1R upregulation, experimental overexpression or its ligand stimulation protects cells, which correlates with reduced ER stress and apoptosis in most studies (Mitsuda et al., 2011; Wang et al., 2012; Omi et al., 2014; Shimazawa et al., 2015; Cao et al., 2017; Ellis et al., 2017; Morihara et al., 2018; Zhai et al., 2019), but not all (Penas et al., 2011; Schrock et al., 2013; Alam et al., 2017). A biphasic role has also been described, with Sig-1R-mediated exacerbation followed by protection, concomitant with increased and reduced markers of ER stress and autophagy response, respectively (Yang et al., 2017). In paragraphs below, evidence supporting a role of Sig- $1 \mathrm{R}$ in modulating several aspects of the ER stress response potentially relevant for $\mathrm{CoV}$ infection is reviewed and discussed.

\section{Endomembrane Remodeling}

ER remodeling is a key early element of ER stress response induced by CoVs. As discussed before, CoVs benefit from endomembrane compartments and induce the growth and remodeling of host cell ER membranes to form a reticulovesicular network (Knoops et al., 2008). Depletion of Sig-1R leads to abnormal ER morphology including loss of ER tethering and proliferation as well as mitochondrial abnormalities and mitophagy, suggesting a role of Sig-1R in maintaining structural and functional integrity of the ER and mitochondria (Vollrath et al., 2014). Thus, pharmacological blocking of Sig-1R might hinder ER remodeling and challenge mitochondrial energy supply, both required for viral replication. This is coherent with the finding that Sig-1R is required at early stages of $\mathrm{HCV}$ replication (Friesland et al., 2013), when ER remodeling and anchoring of the viral replicase complex occurs. Unfortunately, the role played by Sig-1R in architectonics of ER membranes during viral infection has not been investigated.

\section{Calcium Homeostasis}

Viruses have evolved mechanisms to disturb host cell $\mathrm{Ca}^{2+}$ homeostasis and increase intracellular $\mathrm{Ca}^{2+}$ as $\mathrm{Ca}^{2+}$ is essential for virus entry, replication, maturation and release (Olivier, 1996; Chen et al., 2019). Impeding virus-induced abnormal cytosolic $\mathrm{Ca}^{2+}$ increase by blocking $\mathrm{Ca}^{2+}$ release from the $\mathrm{ER}$ or $\mathrm{Ca}^{2+}$ entry through plasma membrane channels/pumps has emerged as a strategy to control viral infections (Chen et al., 2019). Accordingly, some $\mathrm{Ca}^{2+}$ channel blockers have been reported to improve mortality and decrease risk for intubation and mechanical ventilation in elderly patients hospitalized for COVID-19 (Solaimanzadeh, 2020). The Sig-1R regulates both $\mathrm{Ca}^{2+}$ entry at the plasma membrane level (via interaction with ligand- and voltage-gated $\mathrm{Ca}^{2+}$ channels) and $\mathrm{Ca}^{2+}$ mobilization from endoplasmic stores [via interaction with inositol1,4,5 trisphosphate receptors, $\left.\left(\mathrm{IP}_{3} \mathrm{Rs}\right)\right]$ (Monnet, 2005). Under ER stress $\left(\mathrm{Ca}^{2+}\right.$ depletion from ER stores), Sig-1R dissociates from $\mathrm{BiP}$ and chaperones $\mathrm{IP}_{3} \mathrm{R} 3$, ensuring proper $\mathrm{Ca}^{2+}$ signaling from the ER into mitochondria (Hayashi and Su, 2001; Wu and Bowen, 2008) (Figure 3). Increased $\mathrm{IP}_{3} \mathrm{R} 3$-mediated $\mathrm{Ca}^{2+}$ flow to mitochondria at MAM is fundamental for coupling cell physiology to energy demand, which is likely required for virus protein anabolism and RNA synthesis, but sustained/excessive $\mathrm{Ca}^{2+}$ influx into mitochondria results in excessive ROS, oxidative stress and apoptosis. Sig-1R agonists cause dissociation of Sig-1R from BiP, allow Sig-1R- $\mathrm{IP}_{3} \mathrm{R} 3$ interaction and thus enhance $\mathrm{IP}_{3} \mathrm{R} 3$-mediated $\mathrm{Ca}^{2+}$ flow to mitochondria whereas Sig-1R antagonists do not affect the Sig-1R-BiP association but inhibit the dissociation mediated by Sig-1R agonists. A Ying-Yang effect has been described for Sig-1R agonists, by increasing mitochondrial complex I activity and triggering moderate ROS increase in a $\mathrm{Ca}^{2+}$-dependent manner as a physiological signal, but attenuating complex I and IV dysfunctions and promoting a marked anti-oxidant effect in pathological conditions (Goguadze et al., 2019). Treatment of mitochondrial membranes with the Sig-1R agonist (+)-pentazocine leads to phosphorylation of Bad and NADPHdependent production of ROS through Racl signaling (Natsvlishvili et al., 2015). Immunoprecipitation techniques revealed that Sig-1R at MAM form complexes with Rac1, $\mathrm{IP}_{3} \mathrm{R}$ and $\mathrm{Bcl} 2$, and Sig-1R agonists could induce mild oxidative stress through this $\mathrm{IP}_{3} \mathrm{R} / \mathrm{Sig}-1 \mathrm{R} / \mathrm{Bcl} / \mathrm{Racl}$ multiprotein complex (Natsvlishvili et al., 2015). Altogether, both bioenergetic coupling and mitochondrial $\mathrm{Ca}^{2+}$ overflow-mediated apoptosis are dependent on $\mathrm{Ca}^{2+}$ signaling through $\mathrm{IP}_{3} \mathrm{R} 3$ at MAM and are regulated by Sig1R (Delprat et al., 2020). $\mathrm{Ca}^{2+}$ release from ER to cytosol via increased $\mathrm{IP}_{3} \mathrm{R} 1$ activity also induces ER stress and Sig-1R binds to and regulates $\mathrm{IP}_{3} \mathrm{R} 1 \mathrm{~s}$ as well (Kubickova et al., 2018) (Figure 3). Fine tune control (enough for enhanced energy supply but not too much to avoid host cell death) of these mechanisms might be essential for efficient viral infection, thus suggesting that pharmacological modulation of Sig-1R offers here a therapeutic opportunity to counteract the virus program (Figure 3).

\section{Intreraction with Master Unfolded Protein Response Regulators}

Sig-1R binds in a dynamic, reversible and $\mathrm{Ca}^{2+}$-dependent manner to the ER lumenal chaperone and stress sensor BiP (Hayashi and $\mathrm{Su}$, 


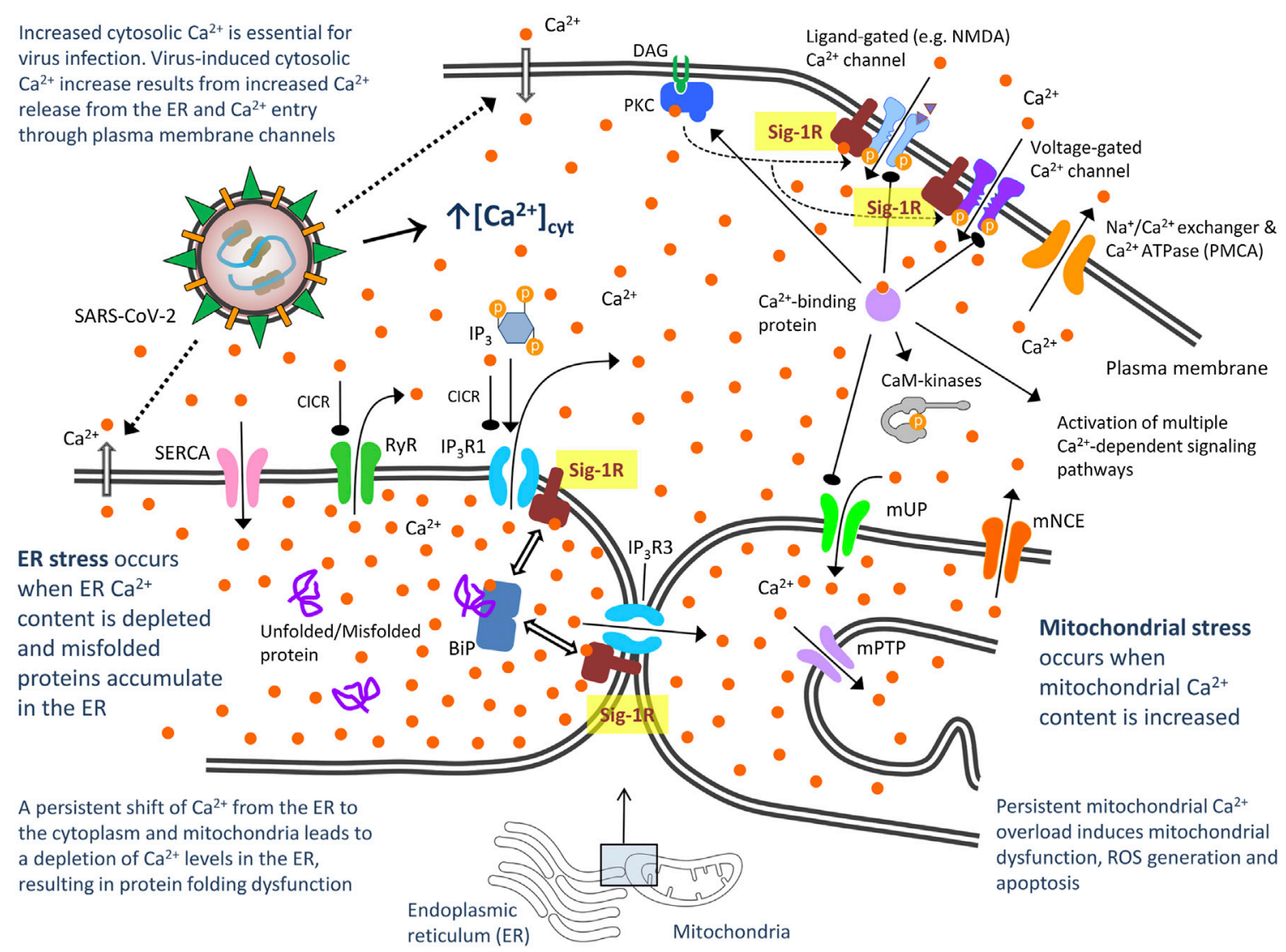

FIGURE 3|Proposed model of severe acute respiratory syndrome CoV-2 (SARS-CoV-2)-mediated disturbance of host cell calcium (Ca ${ }^{2+}$ ) homeostasis: Potential role of Sigma-1 receptors via interaction with $\mathrm{Ca}^{2+}$ channels in the plasma membrane and ER. CaM kinases, Ca ${ }^{2+} / \mathrm{calmodulin}^{2}$ dependent protein kinases; DAG, diacylglycerol; $I P_{3}$, inositol 1,4,5-triphosphate; $I_{3} R s$, inositol 1,4,5-triphosphate receptor-gated channels; $I P_{3} R 1$ mediates ca ${ }^{2+}$ release from $E R$ to cytosol and IP ${ }_{3} R 3$ to mitochondria. They are activated not only by $\mathrm{IP}_{3}$, but also by low $\mathrm{Ca}^{2+}$ concentrations through a process often referred to as $\mathrm{Ca}^{2+}$-induced $\mathrm{Ca}^{2+}$ release $(\mathrm{CICR})$. High cytosolic $\mathrm{Ca}^{2+}$ concentration can instead inhibit $\mathrm{IP}_{3} \mathrm{Rs}$; PKC, protein kinase C; mNCE, mitocondral $\mathrm{Na}^{+} / \mathrm{Ca}^{2+}$ and $2 \mathrm{H}^{+} / \mathrm{Ca}^{2+}$ exchangers. They slowly eject accumulated $\mathrm{Ca}^{2+}$ back into the cytosol; $\mathrm{mPTP}$, mitochondrial permeability transition pore. Once intramitochondrial $\mathrm{Ca}^{2+}$ rises above a certain threshold, this voltageand $\mathrm{Ca}^{2+}$-dependent high-conductance channel in the inner membrane opens, activating cell death mechanisms; mUP, mitochondrial uniporter. It is gated by Ca ${ }^{2+}$ in a biphasic manner. $\mathrm{Ca}^{2+}$ uptake into mitochondria is facilitated by $\mathrm{Ca}^{2+} /$ calmodulin, but sustained cytosolic $\mathrm{Ca}^{2+}$ levels inactivate the uniporter, preventing further $\mathrm{Ca}^{2+}$ uptake; RyR, ryanodine receptor. It is a $\mathrm{Ca}^{2+}$-gated $\mathrm{Ca}^{2+}$ channels $(\mathrm{CICR})$; SERCA, sarco/endoplasmic reticulum $\mathrm{Ca}^{2+} \mathrm{ATPase}^{2}$ It restores ER with $\mathrm{Ca}{ }^{2+}$. Bibliographic references for the role of Sig-1R are provided in the text.

2007; Ortega-Roldan et al., 2013). BiP, also referred to as GRP78, is an important host factor for viral infection. A substantial amount of SARS-CoV S protein accumulates in the ER during infection and induces direct activation of $\mathrm{BiP}$ and UPR selective pathways (Chan et al., 2006). Targeting BiP has the potential to disrupt multiple stages of the viral life and it has recently proposed as a potential therapeutic approach for $\mathrm{CoV}$ infection (Ha et al., 2020). Sig-1R binds the nucleotide-binding domain of $\mathrm{BiP}$ though its bulky C-terminal lumenal domain (Ortega-Roldan et al., 2013). Dissociation of ER membrane-bound Sig-1R from lumenal BiP occurs upon $\mathrm{Ca}^{2+}$ depletion (indicative of ER stress) or pharmacological Sig-1R stimulation (Figure 2). BiP also binds to the ER lumenal domains of membrane-bound UPR transducers PERK and IRE1 and, when bounded, both $\mathrm{BiP}$ and UPR transducers remain in an inactive state. Recruitment of misfolded proteins to $\mathrm{BiP}$ substrate-binding domain during ER stress stimulates ATPase activity within its nucleotidebinding domain, enabling $\mathrm{BiP}$ to adopt an ADP-bound conformation that dissociates from PERK and IRE1 to allow their activation and initiation of UPR signaling cascades (Bertolotti et al., 2000; Kopp et al., 2019). The mechanistic details for Sig-1R modulation of UPR via interaction with $\mathrm{BiP}$ are unknown. Does Sig-1R-BiP dissociation act as a co-activator (together with misfolded proteins and ATP binding) to induce UPR? Does Sig-1R act as an allosteric inductor or compete with PERK and/or IRE1 for binding to the BiP nucleotidebinding domain? Despite these and other unanswered questions, evidence places Sig-1R as a sensor of ER stress $\left(\mathrm{Ca}^{2+}\right.$ depletion $)$ and upstream regulator of UPR. Does it support the antiviral effect of Sig$1 \mathrm{R}$ ligands in numerous cellular assays?

In addition to its interaction with its co-chaperone BiP, Sig-1R also chaperones the ER resident transmembrane protein IRE1 (Mori et al., 2013), one of the ER stress transducers, important for CoVs to adapt host cellular machinery to their demands and antagonize cell apoptosis (Fung et al., 2014b). Sig-1R stabilizes IRE1 when cells are under ER stress and such interaction allows 
conformationally correct IRE1 to dimerize to the activated form (Mori et al., 2013) (Figure 2). IRE1 (alpha isoform, IRE1a) has RNase activity coupled to kinase activity. There are different models proposed for IRE1 activation and all of them involve dissociation from $\mathrm{BiP}$, oligomerization and activation of its cytosolic kinase domain (Adams et al., 2019). This activation allows unconventional splicing of XBP1 mRNA and subsequent translation of an active transcription factor, XBP1s. XBP1s promotes expression of several targets including chaperones, foldases and components of the ERAD pathway in order to restore protein homeostasis (Smith et al., 2011). The envelope E protein of SARS-CoV has been shown to counteract the IRE1/XBP1 pathway of UPR (DeDiego et al., 2011), suggesting that inhibition of the IRE1/XBP1 pathway of UPR is important for $\mathrm{CoV}$ infection. Studies performed on the herpes simplex virus-1 replication showed an opposite action of IRE1 domains on viral replication, RNase activity being unfavorable to viral replication and kinase activity enhancing it (Su et al., 2017). IRE1 RNase activity activates the cellular protein degradation pathway (ERAD) that might lead to the degradation of viral proteins, which is unfavorable to viral replication (Su et al., 2017). Accordingly, in order to facilitate viral replication, IRE1 RNase activity was suppressed in infections by a variety of viruses, including CoV mouse hepatitis virus (MHV) (Bechill et al., 2008). The RNase activity of IRE1 may also target other genes via regulated IRE1-dependent decay (RIDD). RIDD is the mechanism by which IRE1 cleaves target transcript substrates that are degraded and contributes to the maintenance of ER homeostasis by diminishing ER protein load via mRNA degradation, but it has also been proposed to lead to cell death (Tam et al., 2014; Abdullah and Ravanan, 2018). Sig-1R associates to and restricts IRE1 endonuclease (RNAase) activity, needed for splicing the mRNA encoding XBP1 to produce active XBP1 protein in preclinical models of sepsis and inflammation (Rosen et al., 2019). Indeed, LPSchallenged Sig-1R knockout mice had increased hepatic XBP1 splicing when compared to WT mice. The mechanism by which the virus impairs IRE1 RNase activity is unknown, but pharmacological blocking of Sig-1R might promote IRE1 RNase activity and thus increase IRE1/XBP1-dependent degradation pathways. Is it contributing to the inhibitory effect of Sig-1R antagonist ligands on viral replication?

\section{Autophagy}

Finally, CoV infection (inclusive of SARS-CoV, MERS-CoV and the new SARS-CoV-2) has been demonstrated to induce autophagy (Maier and Britton, 2012; Yang and Shen, 2020). Interestingly, expression of viral Nsp6 from diverse CoVs

\section{REFERENCES}

Abate, C., Niso, M., Lacivita, E., Mosier, P. D., Toscano, A., and Perrone, R. (2011). Analogues of $\sigma$ receptor ligand 1-cyclohexyl-4-[3-(5-methoxy-1,2,3,4tetrahydronaphthalen-1-yl)propyl]piperazine (PB28) with added polar functionality and reduced lipophilicity for potential use as positron emission tomography radiotracers. J. Med. Chem. 54, 1022-1032. doi:10.1021/jm1013133

Abdullah, A., and Ravanan, P. (2018). The unknown face of IRE1a - beyond ER stress. Eur. J. Cell Biol. 97, 359-368. doi:10.1016/j.ejcb.2018.05.002 induces autophagy (Cottam et al., 2011). Viral replication proteins from $\mathrm{MHV}$ and SARS CoVs have been shown to colocalize with autophagosome protein markers (Prentice et al., 2004a; Prentice et al., 2004b) and autophagy has been implicated in both the formation of double-membrane vesicles and replication of MHV (Prentice et al., 2004a). However, colocalization of autophagosome markers with specific replicase subunits of SARS-CoV was not observed in other study (Snijder et al., 2006) and a number of observations suggest that autophagy is not directly implicated in viral replication (Zhao et al., 2007). On the contrary, it was reported that MERS-CoV multiplication exerted an inhibitory effect on the autophagy process and that enhancement of autophagy reduced the replication of MERS-CoV (Gassen et al., 2019). Thus, it is controversial whether autophagy is used by viruses in their benefit or whether it actually represents a protective cellular response against $\mathrm{CoV}$ infections. Autophagosomes originate from the ER-mitochondria contact site (Hamasaki et al., 2013) and Sig$1 \mathrm{R}$ acts at this MAM intersection as an upstream modulator of autophagy (Schrock et al., 2013). Sig-1R agonists trigger autophagy after extended treatment, whereas Sig- $1 \mathrm{R}$ antagonists and knockdown of Sig-1R suppresses autophagome formation (Schrock et al., 2013). Accordingly, loss-of-function mutations and Sig-1R deficiency are associated with defective autophagy, leading to accumulation of autophagic vacuoles. In contrast, reexpressing Sig-1R in the null background or its activation restores/induces autophagic activity (Vollrath et al., 2014; MacVicar et al., 2015; Christ et al., 2019; Yang et al., 2019; Christ et al., 2020). Sig-1R is not likely a core component of the general physiological autophagy machinery but it seems needed for cellular stress-induced autophagy (MacVicar et al., 2015). Despite the known interaction of transmembrane SARS-CoV-2 Nsp6 with host Sig-1R protein, the induction of autophagy by Nsp6 and the role played by Sig-1R in autophagy regulation, it is uncertain whether and how Sig-1R is implicated in autophagy induction secondary to $\mathrm{CoV}$ infection.

\section{AUTHOR CONTRIBUTIONS}

The author confirms being the sole contributor of this work and has approved it for publication.

Adams, C. J., Kopp, M. C., Larburu, N., Nowak, P. R., and Ali, M. M. U. (2019) Structure and molecular mechanism of ER stress signaling by the unfolded protein response signal activator IRE1. Front. Mol. Biosci. 6, 11. doi:10.3389/ fmolb.2019.00011

Aimo, A., Baritussio, A., Emdin, M., and Tascini, C. (2020). Amiodarone as a possible therapy for coronavirus infection. Eur. J. Prev. Cardiolog [Epub ahead of print] doi:10.1177/2047487320919233

Aki, T., Nara, A., and Uemura, K. (2012). Cytoplasmic vacuolization during exposure to drugs and other substances. Cell Biol. Toxicol. 28, 125-131. doi:10.1007/s10565-012-9212-3 
Akunne, H. C., Whetzel, S. Z., Wiley, J. N., Corbin, A. E., Ninteman, F. W., Tecle, H., et al. (1997). The pharmacology of the novel and selective sigma ligand, PD 144418. Neuropharmacology 36, 51-62. doi:10.1016/s00283908(96)00161-x

Alam, S., Abdullah, C. S., Aishwarya, R., Orr, A. W., Traylor, J., Miriyala, S., et al. (2017). Sigmarl regulates endoplasmic reticulum stress-induced C/EBPhomologous protein expression in cardiomyocytes. Biosci. Rep. 37 (4), BSR20170898. doi:10.1042/BSR20170898

Alsaadi, J. E. A., and Jones, I. M. (2019). Membrane binding proteins of coronaviruses. Future Virol. 14, 275-286. doi:10.2217/fvl-2018-0144

Azzariti, A., Colabufo, N. A., Berardi, F., Porcelli, L., Niso, M., Simone, G. M., et al. (2006). Cyclohexylpiperazine derivative PB28, a 2 agonist and 1 antagonist receptor, inhibits cell growth, modulates $\mathrm{P}$-glycoprotein, and synergizes with anthracyclines in breast cancer. Mol. Cancer Therapeut. 5, 1807-1816. doi:10. 1158/1535-7163.MCT-05-0402

Baliji, S., Cammer, S. A., Sobral, B., and Baker, S. C. (2009). Detection of nonstructural protein 6 in murine coronavirus-infected cells and analysis of the transmembrane topology by using bioinformatics and molecular approaches. J. Virol. 83, 6957-6962. doi:10.1128/JVI.00254-09

Banerjee, A., Czinn, S. J., Reiter, R. J., and Blanchard, T. G. (2020). Crosstalk between endoplasmic reticulum stress and anti-viral activities: a novel therapeutic target for COVID-19. Life Sci. 255, 117842. doi:10.1016/j.lfs. 2020.117842

Bassetto, M., De Burghgraeve, T., Delang, L., Massarotti, A., Coluccia, A., Zonta, N., et al. (2013). Computer-aided identification, design and synthesis of a novel series of compounds with selective antiviral activity against chikungunya virus. Antivir. Res. 98, 12-18. doi:10.1016/j.antiviral.2013.01.002

Bechill, J., Chen, Z., Brewer, J. W., and Baker, S. C. (2008). Coronavirus infection modulates the unfolded protein response and mediates sustained translational repression. J. Virol. 82, 4492-4501. doi:10.1128/JVI.00017-08

Bertolotti, A., Zhang, Y., Hendershot, L. M., Harding, H. P., and Ron, D. (2000). Dynamic interaction of $\mathrm{BiP}$ and ER stress transducers in the unfolded-protein response. Nat. Cell Biol. 2, 326-332. doi:10.1038/35014014

Boonyasuppayakorn, S., Reichert, E. D., Manzano, M., Nagarajan, K., and Padmanabhan, R. (2014). Amodiaquine, an antimalarial drug, inhibits dengue virus type 2 replication and infectivity. Antivir. Res. 106, 125-134. doi:10.1016/j.antiviral.2014.03.014

Brickelmaier, M., Lugovskoy, A., Kartikeyan, R., Reviriego-Mendoza, M. M., Allaire, N., Simon, K., et al. (2009). Identification and characterization of mefloquine efficacy against JC virus in vitro. Antimicrob. Agents Chemother. 53, 1840-1849. doi:10.1128/AAC.01614-08

Brown, C., Fezoui, M., Selig, W. M., Schwartz, C. E., and Ellis, J. L. (2004). Antitussive activity of sigma-1 receptor agonists in the Guinea-pig. $\mathrm{Br}$. J. Pharmacol. 141, 233-240. doi:10.1038/sj.bjp.0705605

Buschman, H. H. (2007). Use of compounds binding to the sigma receptor for the treatment of diabetes-associated pain. Publication No. WO/2007/025613. International Application No. PCT/EP2006/007419. World Intellectual Property Organization. Also published as United States Patent Application, Publication No. US/2009/0325975, Application No. 11991225.

Cao, Z., Xiao, Q., Dai, X., Zhou, Z., Jiang, R., Cheng, Y., et al. (2017). circHIPK2mediated $\sigma-1 \mathrm{R}$ promotes endoplasmic reticulum stress in human pulmonary fibroblasts exposed to silica. Cell Death Dis. 8, 3212. doi:10.1038/s41419-0170017-4

Carreras-Sureda, A., Pihán, P., and Hetz, C. (2018). Calcium signaling at the endoplasmic reticulum: fine-tuning stress responses. Cell Calcium 70, 24-31. doi:10.1016/j.ceca.2017.08.004

Castaldo, N., Aimo, A., Castiglione, V., Padalino, C., Emdin, M., and Tascini, C. (2020). Safety and efficacy of amiodarone in a patient with COVID-19. J. Am. Coll. Cardiol. 2, 1307-1310. doi:10.1016/j.jaccas.2020.04.053

Chan, C.-P., Siu, K.-L., Chin, K.-T., Yuen, K.-Y., Zheng, B., and Jin, D.-Y. (2006). Modulation of the unfolded protein response by the severe acute respiratory syndrome coronavirus spike protein. J. Virol. 80, 9279-9287. doi:10.1128/JVI. 00659-06

Chan, J. F.-W., Kok, K.-H., Zhu, Z., Chu, H., To, K. K.-W., Yuan, S., et al. (2020). Genomic characterization of the 2019 novel human-pathogenic coronavirus isolated from a patient with atypical pneumonia after visiting Wuhan. Emerg. Microb. Infect. 9, 221-236. doi:10.1080/22221751.2020.1719902
Chen, X., Cao, R., and Zhong, W. (2019). Host calcium channels and pumps in viral infections. Cells 9, 94. doi:10.3390/cells9010094

Cheng, Y.-L., Lan, K.-H., Lee, W.-P., Tseng, S.-H., Hung, L.-R., Lin, H.-C., et al. (2013). Amiodarone inhibits the entry and assembly steps of hepatitis $C$ virus life cycle. Clin. Sci. 125, 439-448. doi:10.1042/CS20120594

Chockalingam, K., Simeon, R. L., Rice, C. M., and Chen, Z. (2010). A cell protection screen reveals potent inhibitors of multiple stages of the hepatitis $C$ virus life cycle. Proc. Natl. Acad. Sci. U.S.A. 107, 3764-3769. doi:10.1073/pnas. 0915117107

Christ, M., Huesmann, H., Nagel, H., Kern, A., and Behl, C. (2019). Sigma-1 receptor activation induces autophagy and increases proteostasis capacity in vitro and in vivo. Cells 8, 211. doi:10.3390/cells8030211

Christ, M. G., Clement, A. M., and Behl, C. (2020). The sigma-1 receptor at the crossroad of proteostasis, neurodegeneration, and autophagy. Trends Neurosci. 43, 79-81. doi:10.1016/j.tins.2019.12.002

Chu, H., Chan, C.-M., Zhang, X., Wang, Y., Yuan, S., Zhou, J., et al. (2018). Middle East respiratory syndrome coronavirus and bat coronavirus HKU9 both can utilize GRP78 for attachment onto host cells. J. Biol. Chem. 293, 11709-11726. doi:10.1074/jbc.RA118.001897

ClinicalTrials.gov Identifier NCT02307591 (2014). Clinical study to assess efficacy and safety of amiodarone in treating patients with Ebola virus disease (EVD) in Sierra Leone. Emergency amiodarone study against Ebola (EASE). Available at: http://www.clinicaltrials.gov/ct2/results?term=NCT02307591 (Accessed July $10,2020)$.

ClinicalTrials.gov query (2020). Search of: interventional studies | COVID19 - list results. Available at: https://clinicaltrials.gov/ct2/results?cond=COVID19\&age_ $\mathrm{v}=\&$ gndr $=\&$ type $=$ Intr\&rslt $=\&$ Search $=$ Apply (Accessed May 28, 2020).

Contreras, P. C., Bremer, M. E., and Rao, T. S. (1990). Accelerated communication GBR-12909 and fluspirilene potently inhibited binding of $[3 \mathrm{H}](+)$ 3-PPP to sigma receptors in rat brain. Life Sci. 47, PL133-PL137. doi:10.1016/00243205(90)90446-x

Cottam, E. M., Maier, H. J., Manifava, M., Vaux, L. C., Chandra-Schoenfelder, P., Gerner, W., et al. (2011). Coronavirus nsp6 proteins generate autophagosomes from the endoplasmic reticulum via an omegasome intermediate. Autophagy 7 , 1335-1347. doi:10.4161/auto.7.11.16642

de Wilde, A. H., Jochmans, D., Posthuma, C. C., Zevenhoven-Dobbe, J. C., van Nieuwkoop, S., Bestebroer, T. M., et al. (2014). Screening of an FDA-approved compound library identifies four small-molecule inhibitors of Middle East respiratory syndrome coronavirus replication in cell culture. Antimicrob. Agents Chemother. 58, 4875-4884. doi:10.1128/AAC.03011-14

DeDiego, M. L., Nieto-Torres, J. L., Jiménez-Guardeño, J. M., Regla-Nava, J. A., Álvarez, E., Oliveros, J. C., et al. (2011). Severe acute respiratory syndrome coronavirus envelope protein regulates cell stress response and apoptosis. PLoS Pathog. 7, e1002315. doi:10.1371/journal.ppat. 1002315

Delprat, B., Crouzier, L., Su, T.-P., and Maurice, T. (2020). At the crossing of ER stress and MAMs: a key role of sigma-1 receptor? Adv. Exp. Med. Biol. 1131, 699-718. doi:10.1007/978-3-030-12457-1_28

Dyall, J., Coleman, C. M., Hart, B. J., Venkataraman, T., Holbrook, M. R., Kindrachuk, J., et al. (2014). Repurposing of clinically developed drugs for treatment of Middle East respiratory syndrome coronavirus infection. Antimicrob. Agents Chemother. 58, 4885-4893. doi:10.1128/AAC.0303614

Dyall, J., Johnson, J. C., Hart, B. J., Postnikova, E., Cong, Y., Zhou, H., et al. (2018). In vitro and in vivo activity of amiodarone against Ebola virus. J. Infect. Dis. 218, S592-S596. doi:10.1093/infdis/jiy345

Ellis, D. Z., Li, L., Park, Y., He, S., Mueller, B., and Yorio, T. (2017). Sigma-1 receptor regulates mitochondrial function in glucose- and oxygen-deprived retinal ganglion cells. Invest. Ophthalmol. Vis. Sci. 58, 2755-2764. doi:10.1167/ iovs.16-19199

Fantini, J., Di Scala, C., Chahinian, H., and Yahi, N. (2020). Structural and molecular modelling studies reveal a new mechanism of action of chloroquine and hydroxychloroquine against SARS-CoV-2 infection. Int. J. Antimicrob. Agents 55, 105960. doi:10.1016/j.ijantimicag.2020.105960

Farias, K. J. S., Machado, P. R. L., and da Fonseca, B. A. L. (2013). Chloroquine inhibits dengue virus type 2 replication in Vero cells but not in C6/36 cells. Sci. World J. 2013, 1. doi:10.1155/2013/282734 
FDA communication (2020). Memorandum explaining basis for revocation of emergency use authorization for emergency use of chloroquine phosphate and hydroxychloroquine sulfate. Available at: https://www.fda.gov/media/138945/ download (Accessed July 10, 2020).

Ferraris, O., Moroso, M., Pernet, O., Emonet, S., Ferrier Rembert, A., Paranhos-Baccalà, G., et al. (2015). Evaluation of Crimean-Congo hemorrhagic fever virus in vitro inhibition by chloroquine and chlorpromazine, two FDA approved molecules. Antivir. Res. 118, 75-81. doi:10.1016/j.antiviral.2015.03.005

Ferris, R. M., Tang, F. L. M., Chang, K.-J., and Russell, A. (1986). Evidence that the potential antipsychotic agent rimcazole (BW 234U) is a specific, competitive antagonist of sigma sites in brain. Life Sci. 38, 2329-2337. doi:10.1016/00243205(86)90640-5

Friesland, M., Mingorance, L., Chung, J., Chisari, F. V., and Gastaminza, P. (2013). Sigma-1 receptor regulates early steps of viral RNA replication at the onset of hepatitis C virus infection. J. Virol. 87, 6377-6390. doi:10.1128/JVI.03557-12

Fung, T. S., Huang, M., and Liu, D. X. (2014a). Coronavirus-induced ER stress response and its involvement in regulation of coronavirus-host interactions. Virus Res. 194, 110-123. doi:10.1016/j.virusres.2014.09.016

Fung, T. S., Liao, Y., and Liu, D. X. (2014b). The endoplasmic reticulum stress sensor IRE1 protects cells from apoptosis induced by the coronavirus infectious bronchitis virus. J. Virol. 88, 12752-12764. doi:10.1128/JVI.02138-14

Fung, T. S., and Liu, D. X. (2014). Coronavirus infection, ER stress, apoptosis and innate immunity. Front. Microbiol. 5, 296. doi:10.3389/fmicb.2014.00296

Gassen, N. C., Niemeyer, D., Muth, D., Corman, V. M., Martinelli, S., Gassen, A., et al. (2019). SKP2 attenuates autophagy through beclin1-ubiquitination and its inhibition reduces MERS-coronavirus infection. Nat. Commun. 10, 5770. doi:10.1038/s41467-019-13659-4

Gastaminza, P., Whitten-Bauer, C., and Chisari, F. V. (2010). Unbiased probing of the entire hepatitis $\mathrm{C}$ virus life cycle identifies clinical compounds that target multiple aspects of the infection. Proc. Natl. Acad. Sci. U.S.A. 107, 291-296. doi:10.1073/pnas.0912966107

Gehring, G., Rohrmann, K., Atenchong, N., Mittler, E., Becker, S., Dahlmann, F., et al. (2014). The clinically approved drugs amiodarone, dronedarone and verapamil inhibit filovirus cell entry. J. Antimicrob. Chemother. 69, 2123-2131. doi:10.1093/jac/dku091

Geleris, J., Sun, Y., Platt, J., Zucker, J., Baldwin, M., Hripcsak, G., et al. (2020). Observational study of hydroxychloroquine in hospitalized patients with covid19. N. Engl. J. Med. 382, 2411-2418. doi:10.1056/NEJMoa2012410

Gilligan, P. J., Kergaye, A. A., Lewis, B. M., and McElroy, J. F. (1994). Piperidinyltetralin sigma. Ligands. J. Med. Chem. 37, 364-370. doi:10.1021/ jm00029a008

Gitto, R., De Luca, L., Ferro, S., Scala, A., Ronsisvalle, S., Parenti, C., et al. (2014). From NMDA receptor antagonists to discovery of selective $\sigma 2$ receptor ligands. Bioorg. Med. Chem. 22, 393-397. doi:10.1016/j.bmc.2013.11.014

Glebov, O. O. (2020). Understanding SARS-CoV-2 endocytosis for COVID-19 drug repurposing. FEBS J. 2020, 15369. doi:10.1111/febs.15369

Goguadze, N., Zhuravliova, E., Morin, D., Mikeladze, D., and Maurice, T. (2019). Sigma-1 receptor agonists induce oxidative stress in mitochondria and enhance complex I activity in physiological condition but protect against pathological oxidative stress. Neurotox. Res. 35, 1-18. doi:10.1007/s12640017-9838-2

Goldman, S. D., Funk, R. S., Rajewski, R. A., and Krise, J. P. (2009). Mechanisms of amine accumulation in, and egress from, lysosomes. Bioanalysis 1, 1445-1459. doi:10.4155/bio.09.128

Gordon, D. E., Jang, G. M., Bouhaddou, M., Xu, J., Obernier, K., White, K. M., et al. (2020). A SARS-CoV-2 protein interaction map reveals targets for drug repurposing. Nature 583, 459-468. doi:10.1038/s41586-020-2286-9

Gosert, R., Kanjanahaluethai, A., Egger, D., Bienz, K., and Baker, S. C. (2002). RNA replication of mouse hepatitis virus takes place at double-membrane vesicles. J. Virol. 76, 3697-3708. doi:10.1128/jvi.76.8.3697-3708.2002.

Gregori-Puigjané, E., Setola, V., Hert, J., Crews, B. A., Irwin, J. J., Lounkine, E., et al. (2012). Identifying mechanism-of-action targets for drugs and probes. Proc. Natl. Acad. Sci. U.S.A. 109, 11178-11183. doi:10.1073/pnas.1204524109

Guo, L., Zhao, J., Jin, G., Zhao, B., Wang, G., Zhang, A., et al. (2013). SKF83959 is a potent allosteric modulator of sigma-1 receptor. Mol. Pharmacol. 83, 577-586. doi:10.1124/mol.112.083840

Gupta-Wright, A., Lavers, J., and Irvine, S. (2015). Concerns about the off-licence use of amiodarone for Ebola. BMJ 350, h272. doi:10.1136/bmj.h272
Ha, D. P., Van Krieken, R., Carlos, A. J., and Lee, A. S. (2020). The stress-inducible molecular chaperone GRP78 as potential therapeutic target for Coronavirus infection. J. Infect. 81, 452-482. doi:10.1016/j.jinf.2020.06.017

Hamasaki, M., Furuta, N., Matsuda, A., Nezu, A., Yamamoto, A., Fujita, N., et al. (2013). Autophagosomes form at ER-mitochondria contact sites. Nature 495, 389-393. doi:10.1038/nature 11910

Hanner, M., Moebius, F. F., Flandorfer, A., Knaus, H. G., Striessnig, J., Kempner, E., et al. (1996). Purification, molecular cloning, and expression of the mammalian sigma1-binding site. Proc. Natl. Acad. Sci. U.S.A. 93, 8072-8077. doi:10.1073/ pnas.93.15.8072

Hashimoto, K., and London, E. D. (1995). Interactions of erythro-ifenprodil, threo-ifenprodil, erythro-iodoifenprodil, and eliprodil with subtypes of $\sigma$ receptors. Eur. J. Pharmacol. 273, 307-310. doi:10.1016/0014-2999(94) 00763-w

Hayashi, T., and Su, T.-P. (2001). Regulating ankyrin dynamics: roles of sigma-1 receptors. Proc. Natl. Acad. Sci. U.S.A. 98, 491-496. doi:10.1073/pnas. 02141369810.1073/pnas.98.2.491

Hayashi, T., and Su, T.-P. (2007). Sigma-1 receptor chaperones at the ERmitochondrion interface regulate Ca2+ signaling and cell survival. Cell 131, 596-610. doi:10.1016/j.cell.2007.08.036

Hayashi, T. (2019). The sigma-1 receptor in cellular stress signaling. Front. Neurosci. 13, 733. doi:10.3389/fnins.2019.00733

He, Y.-L., Zhang, C.-L., Gao, X.-F., Yao, J.-J., Hu, C.-L., and Mei, Y.-A. (2012). Cyproheptadine enhances the Ik of mouse cortical neurons through sigma-1 receptor-mediated intracellular signal pathway. PLoS One 7, e41303. doi:10. 1371/journal.pone. 0041303

Hirata, Y., Yamamoto, H., Atta, M. S. M., Mahmoud, S., Oh-hashi, K., and Kiuchi, K. (2011). Chloroquine inhibits glutamate-induced death of a neuronal cell line by reducing reactive oxygen species through sigma-1 receptor. J. Neurochem. 119, 839-847. doi:10.1111/j.1471-4159.2011.07464.x

Homolak, J., and Kodvanj, I. (2020). Widely available lysosome targeting agents should be considered as potential therapy for COVID-19. Int. J. Antimicrob. Agents 56, 106044. doi:10.1016/j.ijantimicag.2020.106044

Huang, F., Zhang, C., Liu, Q., Zhao, Y., Zhang, Y., Qin, Y., et al. (2020). Identification of amitriptyline $\mathrm{HCl}$, flavin adenine dinucleotide, azacitidine and calcitriol as repurposing drugs for influenza A H5N1 virus-induced lung injury. PLoS Pathog. 16 (3), e1008341), e1008341. doi:10.1371/journal.ppat. 1008341

Husbands, S. M., Izenwasser, S., Kopajtic, T., Bowen, W. D., Vilner, B. J., Katz, J. L., et al. (1999). Structure-activity relationships at the monoamine transporters and $\sigma$ receptors for a novel series of 9-[3-(cis-3,5-Dimethyl-1-piperazinyl)propyl]carbazole (rimcazole) analogues. J. Med. Chem. 42, 4446-4455. doi:10. $1021 /$ jm 9902943

Ibrahim, I. M., Abdelmalek, D. H., Elshahat, M. E., and Elfiky, A. A. (2020) COVID-19 spike-host cell receptor GRP78 binding site prediction. J. Infect. 80, 554-562. doi:10.1016/j.jinf.2020.02.026

Jeon, S., Ko, M., Lee, J., Choi, I., Byun, S. Y., Park, S., et al. (2020). Identification of antiviral drug candidates against SARS-CoV-2 from FDA-approved drugs. Antimicrob. Agents Chemother. 64 (7), e00819-20. doi:10.1128/AAC.0081920

Johansen, L. M., Brannan, J. M., Delos, S. E., Shoemaker, C. J., Stossel, A., Lear, C., et al. (2013). FDA-approved selective estrogen receptor modulators inhibit Ebola virus infection. Sci. Transl. Med. 5 (190), 190ra79. doi:10.1126/ scitranslmed.3005471

Johansen, L. M., DeWald, L. E., Shoemaker, C. J., Hoffstrom, B. G., Lear-Rooney, C. M., Stossel, A., et al. (2015). A screen of approved drugs and molecular probes identifies therapeutics with anti-Ebola virus activity. Sci. Transl. Med. 7 (290), 290ra89. doi:10.1126/scitranslmed.aaa5597

Karagöz, G. E., Aragón, T., and Acosta-Alvear, D. (2019). Recent advances in signal integration mechanisms in the unfolded protein response, F1000Res. 8, 1840. doi:10.12688/f1000research.19848.1

Kaufmann, A. M., and Krise, J. P. (2007). Lysosomal sequestration of aminecontaining drugs: analysis and therapeutic implications. J. Pharmaceut. Sci. 96, 729-746. doi:10.1002/jps.20792

Keyaerts, E., Li, S., Vijgen, L., Rysman, E., Verbeeck, J., Van Ranst, M., et al. (2009). Antiviral activity of chloroquine against human coronavirus OC43 infection in newborn mice. Antimicrob. Agents Chemother. 53, 3416-3421. doi:10.1128/ AAC.01509-08 
Keyaerts, E., Vijgen, L., Maes, P., Neyts, J., and Ranst, M. V. (2004) In vitro inhibition of severe acute respiratory syndrome coronavirus by chloroquine. Biochem. Biophys. Res. Commun. 323, 264-268. doi:10.1016/j.bbrc.2004.08. 085

Kim, R., Emi, M., Tanabe, K., and Murakami, S. (2006). Role of the unfolded protein response in cell death. Apoptosis 11, 5-13. doi:10.1007/s10495-0053088-0

Klein, M., and Musacchio, J. M. (1989). High affinity dextromethorphan binding sites in Guinea pig brain. Effect of sigma ligands and other agents. J. Pharmacol. Exp. Therapeut. 251, 207-215.

Knoops, K., Kikkert, M., Worm, S. H. E. v. d., Zevenhoven-Dobbe, J. C., van der Meer, Y., Koster, A. J., et al. (2008). SARS-coronavirus replication is supported by a reticulovesicular network of modified endoplasmic reticulum. PLoS Biol. 6, e226. doi:10.1371/journal.pbio.0060226

Kopp, M. C., Larburu, N., Durairaj, V., Adams, C. J., and Ali, M. M. U. (2019). UPR proteins IRE1 and PERK switch BiP from chaperone to ER stress sensor. Nat. Struct. Mol. Biol. 26, 1053-1062. doi:10.1038/s41594-0190324-9

Kubickova, J., Lencesova, L., Csaderova, L., Stracina, T., Hudecova, S., Babula, P., et al. (2018). Haloperidol affects plasticity of differentiated NG-108 cells through o1R/IP3R1 complex. Cell. Mol. Neurobiol. 38, 181-194. doi:10.1007/ s10571-017-0524-y

Laggner, C., Schieferer, C., Fiechtner, B., Poles, G., Hoffmann, R. D., Glossmann, H., et al. (2005). Discovery of high-affinity ligands of o1Receptor, ERG2, and emopamil binding protein by pharmacophore modeling and virtual screening. J. Med. Chem. 48, 4754-4764. doi:10. 1021/jm049073+

Lang, A., Soosaar, A., Kõks, S., Volke, K., Bourin, M., Bradwejn, J., et al. (1994). Pharmacological comparison of antipsychotic drugs and $\sigma$-antagonists in rodents. Pharmacol. Toxicol. 75, 222-227. doi:10.1111/j.1600-0773.1994. tb00351.x

Largent, B. L., Gundlach, A. L., and Snyder, S. H. (1984). Psychotomimetic opiate receptors labeled and visualized with (+)-[3H]3-(3-hydroxyphenyl)-N-(1propyl)piperidine. Proc. Natl. Acad. Sci. U.S.A. 81, 4983-4987. doi:10.1073/ pnas.81.15.4983

Larson, H. E., Reed, S. E., and Tyrrell, D. A. J. (1980). Isolation of rhinoviruses and coronaviruses from 38 colds in adults. J. Med. Virol. 5, 221-229. doi:10.1002/ jmv.1890050306

Lee, W., Yoo, W., and Chae, H. (2015). ER stress and autophagy. Curr. Mol. Med. 15, 735-745. doi:10.2174/1566524015666150921105453

Lever, J. R., Litton, T. P., and Fergason-Cantrell, E. A. (2015). Characterization of pulmonary sigma receptors by radioligand binding. Eur. J. Pharmacol. 762, 118-126. doi:10.1016/j.ejphar.2015.05.026

Lever, J. R., Miller, D. K., Fergason-Cantrell, E. A., Green, C. L., Watkinson, L. D., Carmack, T. L., et al. (2014). Relationship between cerebral sigma-1 receptor occupancy and attenuation of cocaine's motor stimulatory effects in mice by PD144418. J. Pharmacol. Exp. Therapeut. 351, 153-163. doi:10.1124/jpet.114. 216671

MacVicar, T., Mannack, L., Lees, R., and Lane, J. (2015). Targeted siRNA screens identify ER-to-mitochondrial calcium exchange in autophagy and mitophagy responses in RPE1 cells. Int. J. Mol. Sci. 16, 13356-13380. doi:10.3390/ ijms160613356

Madrid, P. B., Chopra, S., Manger, I. D., Gilfillan, L., Keepers, T. R., Shurtleff, A. C., et al. (2013). A systematic screen of FDA-approved drugs for inhibitors of biological threat agents. PLoS One 8, e60579. doi:10.1371/journal.pone. 0060579

Madrid, P. B., Panchal, R. G., Warren, T. K., Shurtleff, A. C., Endsley, A. N., Green, C. E., et al. (2015). Evaluation of Ebola virus inhibitors for drug repurposing. ACS Infect. Dis. 1, 317-326. doi:10.1021/acsinfecdis.5b00030

Maier, H., and Britton, P. (2012). Involvement of autophagy in coronavirus replication. Viruses 4, 3440-3451. doi:10.3390/v4123440

Marceau, F., Bawolak, M.-T., Lodge, R., Bouthillier, J., Gagné-Henley, A., C.-Gaudreault, R., et al. (2012). Cation trapping by cellular acidic compartments: beyond the concept of lysosomotropic drugs. Toxicol. Appl. Pharmacol. 259, 1-12. doi:10.1016/j. taap.2011.12.004

Masters, P. S. (2006). The molecular biology of coronaviruses. Adv. Virus Res. 66, 193-292. doi:10.1016/S0065-3527(06)66005-3
Mercer, J., Schelhaas, M., and Helenius, A. (2010). Virus entry by endocytosis. Annu. Rev. Biochem. 79, 803-833. doi:10.1146/annurev-biochem-060208104626

Millet, J. K., and Whittaker, G. R. (2015). Host cell proteases: critical determinants of coronavirus tropism and pathogenesis. Virus Res. 202, 120-134. doi:10.1016/ j.virusres.2014.11.021.

Minakshi, R., Padhan, K., Rani, M., Khan, N., Ahmad, F., and Jameel, S. (2009). The SARS Coronavirus 3a protein causes endoplasmic reticulum stress and induces ligand-independent downregulation of the type 1 interferon receptor. PLoS One 4 (12), e8342-e8342. doi:10.1371/journal.pone.0008342

Mingorance, L., Friesland, M., Coto-Llerena, M., Pérez-del-Pulgar, S., Boix, L., López-Oliva, J. M., et al. (2014). Selective inhibition of hepatitis C virus infection by hydroxyzine and benztropine. Antimicrob. Agents Chemother. 58, 3451-3460. doi:10.1128/AAC.02619-14

Mirabelli, C., Wotring, J. W., Zhang, C. J., McCarty, S. M., Fursmidt, R., Frum, T., et al. (2020). Morphological cell profiling of SARS-CoV-2 infection identifies drug repurposing candidates for COVID-19. Version 2. bioRxiv doi:10.1101/ 2020.05.27.117184

Mitjà, O., Corbacho-Monné, M., Ubals, M., Tebe, C., Peñafiel, J., Tobias, A., et al. (2020). Hydroxychloroquine for early treatment of adults with mild covid-19: a randomized-controlled trial. Clin. Infect. Dis. [Epub ahead of print] ciaal009. doi:10.1093/cid/ciaa1009

Mitsuda, T., Omi, T., Tanimukai, H., Sakagami, Y., Tagami, S., Okochi, M., et al. 2011). Sigma-1Rs are upregulated via PERK/eIF2 $\alpha / A T F 4$ pathway and execute protective function in ER stress. Biochem. Biophys. Res. Commun. 415, 519-525. doi:10.1016/j.bbrc.2011.10.113

Moebius, F. F., Reiter, R. J., Hanner, M., and Glossmann, H. (1997). High affinity of sigmal -binding sites for sterol isomerization inhibitors: evidence for a pharmacological relationship with the yeast sterol C8 -C7 isomerase. $\mathrm{Br}$. J. Pharmacol. 121, 1-6. doi:10.1038/sj.bjp.0701079.

Monnet, F. P. (2005). Sigma-1 receptor as regulator of neuronal intracellular $\mathrm{Ca} 2+$ : clinical and therapeutic relevance. Biol. Cell. 97, 873-883. doi:10.1042/ BC20040149

Mori, T., Hayashi, T., Hayashi, E., and Su, T.-P. (2013). Sigma-1 receptor chaperone at the ER-mitochondrion interface mediates the mitochondrionER-nucleus signaling for cellular survival. PLoS One 8 (10), e76941. doi:10. 1371/journal.pone.0076941

Morihara, R., Yamashita, T., Liu, X., Nakano, Y., Fukui, Y., Sato, K., et al. (2018). Protective effect of a novel sigma-1 receptor agonist is associated with reduced endoplasmic reticulum stress in stroke male mice. J. Neurosci. Res. 96, 1707-1716. doi:10.1002/jnr.24270

Murakami, Y., Fukasawa, M., Kaneko, Y., Suzuki, T., Wakita, T., and Fukazawa, H. (2013). Selective estrogen receptor modulators inhibit hepatitis C virus infection at multiple steps of the virus life cycle. Microb. Infect. 15, 45-55. doi:10.1016/j.micinf.2012.10.003

Musacchio, J. M., and Klein, M. (1988). Dextromethorphan binding sites in the Guinea pig brain. Cell. Mol. Neurobiol. 8, 149-156. doi:10.1007/BF00711241

Nadanaciva, S., Lu, S., Gebhard, D. F., Jessen, B. A., Pennie, W. D., and Will, Y. (2011). A high content screening assay for identifying lysosomotropic compounds. Toxicol. Vitro 25, 715-723. doi:10.1016/j.tiv.2010.12.010

Narita, N., Hashimoto, K., Tomitaka, S.-i., and Minabe, Y. (1996). Interactions of selective serotonin reuptake inhibitors with subtypes of $\sigma$ receptors in rat brain. Eur. J. Pharmacol. 307, 117-119. doi:10.1016/0014-2999(96)00254-3

Natsvlishvili, N., Goguadze, N., Zhuravliova, E., and Mikeladze, D. (2015). Sigma-1 receptor directly interacts with Racl-GTPase in the brain mitochondria. BMC Biochem. 16, 11. doi:10.1186/s12858-015-0040-y

Nemerow, G. R., and Cooper, N. R. (1984). Infection of B lymphocytes by a human herpesvirus, Epstein-Barr virus, is blocked by calmodulin antagonists. Proc. Natl. Acad. Sci. U.S.A. 81, 4955-4959. doi:10.1073/pnas.81.15.4955

Nobile, B., Durand, M., Courtet, P., Van de Perre, P., Nagot, N., Molès, J. P., et al. (2020). Could the antipsychotic chlorpromazine be a potential treatment for SARS-CoV-2? Schizophr. Res. [Epub ahead of print] S0920-9964. doi:10.1016/j. schres.2020.07.015

Nugent, K. M., and Shanley, J. D. (1984). Verapamil inhibits influenza A virus replication. Arch. Virol. 81, 163-170. doi:10.1007/BF01309305

Olivier, M. (1996). Modulation of host cell intracellular Ca2+. Parasitol. Today 12, 145-150. doi:10.1016/0169-4758(96)10006-5 
Omi, T., Tanimukai, H., Kanayama, D., Sakagami, Y., Tagami, S., Okochi, M., et al. (2014). Fluvoxamine alleviates ER stress via induction of Sigma-1 receptor. Cell Death Dis. 5, e1332. doi:10.1038/cddis.2014.301

Ooi, E., Chew, J., Loh, J., and Chua, R. C. (2006). In vitro inhibition of human influenza A virus replication by chloroquine. Virol. J. 3, 39. doi:10.1186/1743$422 \mathrm{X}-3-39$

Oostra, M., Hagemeijer, M. C., van Gent, M., Bekker, C. P. J., te Lintelo, E. G., Rottier, P. J. M., et al. (2008). Topology and membrane anchoring of the coronavirus replication complex: not all hydrophobic domains of nsp3 and nsp6 are membrane spanning. J. Virol. 82, 12392-12405. doi:10.1128/JVI. 01219-08

Ortega-Roldan, J. L., Ossa, F., and Schnell, J. R. (2013). Characterization of the human sigma-1 receptor chaperone domain structure and binding immunoglobulin protein (BiP) interactions. J. Biol. Chem. 288, 21448-21457. doi:10.1074/jbc.M113.450379

Pabba, M. (2013). The essential roles of protein-protein interaction in sigma-1 receptor functions. Front. Cell. Neurosci. 7, 50. doi:10.3389/fncel.2013. 00050

Palmeira, V. A., Costa, L. B., Perez, L. G., Ribeiro, V. T., Lanza, K., and Silva, A. C. S. E. (2020). Do we have enough evidence to use chloroquine/ hydroxychloroquine as a public health panacea for COVID-19? Clinics 75 , e1928. doi:10.6061/clinics/2020/e1928. https://www.ncbi.nlm.nih.gov/pmc/ articles/PMC7199295/

Pascual, R., Almansa, C., Plata-Salamán, C., and Vela, J. M. (2019). A new pharmacophore model for the design of sigma-1 ligands validated on a large experimental dataset. Front. Pharmacol. 10, 519. doi:10.3389/fphar. 2019.00519

PDSP Ki Database. Available at: https://pdsp.unc.edu/databases/kidb.php (Accessed May 28, 2020). doi:10.4016/38362.01. http://www.scivee.tv/node/ 38362

Penas, C., Pascual-Font, A., Mancuso, R., Forés, J., Casas, C., and Navarro, X. (2011). Sigma receptor agonist 2-(4-morpholinethyl)1 phenylcyclohexanecarboxylate (Pre084) increases GDNF and BiP expression and promotes neuroprotection after root avulsion injury. J. Neurotrauma 28, 831-840. doi:10.1089/neu.2010. 1674

Perregaard, J., Moltzen, E. K., Meier, E., and Sánchez, C. (1995). sigma. Ligands with subnanomolar affinity and preference for the sigma.2 binding site. 1. 3(.omega.-Aminoalkyl)-1H-indoles. J. Med. Chem. 38, 1998-2008. doi:10.1021/ jm00011a019

Pillay, T. S. (2020). Gene of the month: the 2019-nCoV/SARS-CoV-2 novel coronavirus spike protein. J. Clin. Pathol. 73, 366-369. doi:10.1136/ jclinpath-2020-206658

Plaze, M., Attali, D., Petit, A.-C., Blatzer, M., Simon-Loriere, E., Vinckier, F., et al. (2020). Repurposing chlorpromazine to treat COVID-19: the recovery study. L’Encéphale 46, 169-172. doi:10.1016/j.encep.2020.05.006

Pohjala, L., Utt, A., Varjak, M., Lulla, A., Merits, A., Ahola, T., et al. (2011). Inhibitors of alphavirus entry and replication identified with a stable Chikungunya replicon cell line and virus-based assays. PLoS One 6 (12), e28923. doi:10.1371/journal.pone.0028923

Prentice, E., Jerome, W. G., Yoshimori, T., Mizushima, N., and Denison, M. R. (2004a). Coronavirus replication complex formation utilizes components of cellular autophagy. J. Biol. Chem. 279, 10136-10141. doi:10.1074/jbc. M306124200

Prentice, E., McAuliffe, J., Lu, X., Subbarao, K., and Denison, M. R. (2004b). Identification and characterization of severe acute respiratory syndrome coronavirus replicase proteins. J. Virol. 78, 9977-9986. doi:10.1128/JVI.78. 18.9977-9986.2004

Rashid, H.-O., Yadav, R. K., Kim, H.-R., and Chae, H.-J. (2015). ER stress: autophagy induction, inhibition and selection. Autophagy 11, 1956-1977. doi:10.1080/15548627.2015.1091141

Romero, L., Zamanillo, D., Nadal, X., Sánchez-Arroyos, R., Rivera-Arconada, I., Dordal, A., et al. (2012). Pharmacological properties of S1RA, a new sigma-1 receptor antagonist that inhibits neuropathic pain and activity-induced spinal sensitization. Br. J. Pharmacol. 166, 2289-2306. doi:10.1111/j.1476-5381.2012. 01942.x

Rosen, D. A., Seki, S. M., Fernández-Castañeda, A., Beiter, R. M., Eccles, J. D., Woodfolk, J. A., et al. (2019). Modulation of the sigma-1 receptor-IRE1 pathway is beneficial in preclinical models of inflammation and sepsis. Sci. Transl. Med. 11 (478), eaau5266. doi:10.1126/scitranslmed.aau5266

Roth, M. D., Whittaker, K. M., Choi, R., Tashkin, D. P., and Baldwin, G. C. (2005). Cocaine and -1 receptors modulate HIV infection, chemokine receptors, and the HPA axis in the huPBL-SCID model. J. Leukoc. Biol. 78, 1198-1203. doi:10. 1189/jlb.0405219

Roustit, M., Guilhaumou, R., Molimard, M., Drici, M.-D., Laporte, S., Montastruc, J.-L., et al. (2020). Chloroquine and hydroxychloroquine in the management of COVID-19: much kerfuffle but little evidence. Therapie (Paris) 75, 363-370. doi:10.1016/j.therap.2020.05.010

Salata, C., Baritussio, A., Munegato, D., Calistri, A., Ha, H. R., Bigler, L., et al. (2015). Amiodarone and metabolite MDEA inhibit Ebola virus infection by interfering with the viral entry process. Pathog. Dis. 73, ftv032. doi:10.1093/ femspd/ftv032

Sanchis-Gomar, F., Lavie, C. J., Morin, D. P., Perez-Quilis, C., Laukkanen, J. A., and Perez, M. V. (2020). Amiodarone in the COVID-19 era: treatment for symptomatic patients only, or drug to prevent infection? Am. J. Cardiovasc. Drugs 20, 413-418. doi:10.1007/s40256-020-00429-7https://link.springer.com/ article/10.1007/s40256-020-00429-7?error=cookies_not_ supported\&code $=$ d0858ce7-973a-4572-86c5-beec4f806f5f

Savarino, A., Gennero, L., Sperber, K., and Boelaert, J. R. (2001). The anti-HIV-1 activity of chloroquine. J. Clin. Virol. 20, 131-135. doi:10.1016/s1386-6532(00) 00139-6

Schotte, A., Janssen, P. F. M., Gommeren, W., Luyten, W. H. M. L., Van Gompel, P., Lesage, A. S., et al. (1996). Risperidone compared with new and reference antipsychotic drugs: in vitro and in vivo receptor binding. Psychopharmacology 124, 57-73. doi:10.1007/BF02245606

Schrock, J. M., Spino, C. M., Longen, C. G., Stabler, S. M., Marino, J. C., Pasternak, G. W., et al. (2013). Sequential cytoprotective responses to Sigma1 ligandinduced endoplasmic reticulum stress. Mol. Pharmacol. 84, 751-762. doi:10. 1124/mol.113.087809

Shimazawa, M., Sugitani, S., Inoue, Y., Tsuruma, K., and Hara, H. (2015). Effect of a sigma-1 receptor agonist, cutamesine dihydrochloride (SA4503), on photoreceptor cell death against light-induced damage. Exp. Eye Res. 132, 64-72. doi:10.1016/j.exer.2015.01.017

Sieczkarski, S. B., and Whittaker, G. R. (2002). Dissecting virus entry via endocytosis. J. Gen. Virol. 83, 1535-1545. doi:10.1099/0022-1317-83-71535

Siu, K.-L., Chan, C.-P., Kok, K.-H., Woo, P. C.-Y., and Jin, D.-Y. (2014). Comparative analysis of the activation of unfolded protein response by spike proteins of severe acute respiratory syndrome coronavirus and human coronavirus HKU1. Cell Biosci. 4, 3. doi:10.1186/2045-3701-4-3

Smith, M. H., Ploegh, H. L., and Weissman, J. S. (2011). Road to ruin: targeting proteins for degradation in the endoplasmic reticulum. Science 334, 1086-1090. doi:10.1126/science. 1209235

Snijder, E. J., van der Meer, Y., Zevenhoven-Dobbe, J., Onderwater, J. J. M., van der Meulen, J., Koerten, H. K., et al. (2006). Ultrastructure and origin of membrane vesicles associated with the severe acute respiratory syndrome coronavirus replication complex. J .Virol. 80, 5927-5940. doi:10.1128/JVI. 02501-05

Sola, I., Almazán, F., Zúñiga, S., and Enjuanes, L. (2015). Continuous and discontinuous RNA synthesis in coronaviruses. Annu. Rev. Virol. 2, 265-288. doi:10.1146/annurev-virology-100114-055218

Solaimanzadeh, I. (2020). Nifedipine and amlodipine are associated with improved mortality and decreased risk for intubation and mechanical ventilation in elderly patients hospitalized for COVID-19. Cureus 12 (5), e8069. doi:10.7759/ cureus.8069 https://www.cureus.com/articles/31377-nifedipine-and-amlodipineare-associated-with-improved-mortality-and-decreased-risk-for-intubation-andmechanical-ventilation-in-elderly-patients-hospitalized-for-covid-19

Song, S., Tan, J., Miao, Y., Li, M., and Zhang, Q. (2017). Crosstalk of autophagy and apoptosis: involvement of the dual role of autophagy under ER stress. J. Cell. Physiol. 232, 2977-2984. doi:10.1002/jcp.25785

Sperber, K., Kalb, T. H., Stecher, V. J., Banerjee, R., and Mayer, L. (1993). Inhibition of human immunodeficiency virus type 1 replication by hydroxychloroquine in $\mathrm{T}$ cells and monocytes. AIDS Res. Hum. Retrovir. 9, 91-98. doi:10.1089/aid.1993.9.91

Stadler, K., Ha, H. R., Ciminale, V., Spirli, C., Saletti, G., Schiavon, M., et al. (2008). Amiodarone alters late endosomes and inhibits SARS coronavirus infection at a 
post-endosomal level. Am. J. Respir. Cell Mol. Biol. 39, 142-149. doi:10.1165/ rcmb.2007-0217OC

Stone, J. M., Årstad, E., Erlandsson, K., Waterhouse, R. N., Ell, P. J., and Pilowsky, L. S. (2006). [123I]TPCNE-A novel SPET tracer for the sigma-1 receptor: first human studies and in vivo haloperidol challenge. Synapse 60, 109-117. doi:10. $1002 /$ syn.20281

Su, A., Wang, H., Li, Y., Wang, X., Chen, D., and Wu, Z. (2017). Opposite roles of RNase and kinase activities of inositol-requiring enzyme 1 (IRE1) on HSV-1 replication. Viruses 9, 235. doi:10.3390/v9090235http://www.mdpi.com/1999$4915 / 9 / 9 / 235$

Su, T.-P., Hayashi, T., Maurice, T., Buch, S., and Ruoho, A. E. (2010). The sigma-1 receptor chaperone as an inter-organelle signaling modulator. Trends Pharmacol. Sci. 31, 557-566. doi:10.1016/j.tips.2010.08.007

$\mathrm{Su}$, T. P. (1982). Evidence for sigma opioid receptor: binding of [3H]SKF-10047 to etorphine-inaccessible sites in Guinea-pig brain. J. Pharmacol. Exp. Therapeut. 223, 284-290.

$\mathrm{Su}$, T.-P. (1991). Sigma receptors. Putative links between nervous, endocrine and immune systems. Eur. J. Biochem. 200, 633-642. doi:10.1111/j.1432-1033.1991. tb16226.x

Sureda, A., Alizadeh, J., Nabavi, S. F., Berindan-Neagoe, I., Cismaru, C. A., Jeandet, P., et al. (2020). Endoplasmic reticulum as a potential therapeutic target for covid-19 infection management? Eur. J. Pharmacol. 882, 173288. doi:10.1016/j. ejphar.2020.173288

Tam, A. B., Koong, A. C., and Niwa, M. (2014). Ire1 has distinct catalytic mechanisms for XBP1/HAC1 splicing and RIDD. Cell Rep. 9, 850-858. doi:10.1016/j.celrep.2014.09.016

Tam, S. W. (1983). Naloxone-inaccessible sigma receptor in rat central nervous system. Proc. Natl. Acad. Sci. U.S.A. 80, 6703-6707. doi:10.1073/pnas.80.21.6703

Tam, S. W., and Cook, L. (1984). Sigma opiates and certain antipsychotic drugs mutually inhibit (+)-[3H] SKF 10,047 and [3H]haloperidol binding in Guinea pig brain membranes. Proc. Natl. Acad. Sci. U.S.A. 81, 5618-5621. doi:10.1073/ pnas.81.17.5618

Tripathy, S., Dassarma, B., Roy, S., Chabalala, H., and Matsabisa, M. G. (2020). A review on possible modes of action of chloroquine/hydroxychloroquine: repurposing against SAR-CoV-2 (COVID-19) pandemic. Int. J. Antimicrob. Agents 56, 106028. doi:10.1016/j.ijantimicag.2020.106028

Turone, F. (2014). Doctors trial amiodarone for Ebola in Sierra Leone. BMJ 349, g7198. doi:10.1136/bmj.g7198

Vasallo, C., and Gastaminza, P. (2015). Cellular stress responses in hepatitis C virus infection: mastering a two-edged sword. Virus Res. 209, 100-117. doi:10.1016/j. virusres.2015.03.013

Vollrath, J. T., Sechi, A., Dreser, A., Katona, I., Wiemuth, D., Vervoorts, J., et al. (2014). Loss of function of the ALS protein SigR1 leads to ER pathology associated with defective autophagy and lipid raft disturbances. Cell Death Dis. 5 (6), e1290. doi:10.1038/cddis.2014.243

Wędrowska, E., Wandtke, T., Senderek, T., Piskorska, E., and Kopiński, P. (2020). Coronaviruses fusion with the membrane and entry to the host cell. Ann. Agric. Environ. Med. 27, 175-183. doi:10.26444/aaem/122079

Wang, L.-F., Lin, Y.-S., Huang, N.-C., Yu, C.-Y., Tsai, W.-L., Chen, J.-J., et al. (2015). Hydroxychloroquine-inhibited dengue virus is associated with host defense machinery. J. Interferon Cytokine Res. 35, 143-156. doi:10.1089/jir. 2014.0038

Wang, L., Eldred, J. A., Sidaway, P., Sanderson, J., Smith, A. J. O., Bowater, R. P., et al. (2012). Sigma 1 receptor stimulation protects against oxidative damage through suppression of the ER stress responses in the human lens. Mech. Ageing Dev. 133, 665-674. doi:10.1016/j.mad.2012.09.005

Weber, E., Sonders, M., Quarum, M., McLean, S., Pou, S., and Keana, J. F. (1986). 1,3-Di(2-[5-3H]tolyl)guanidine: a selective ligand that labels sigma-type receptors for psychotomimetic opiates and antipsychotic drugs. Proc. Natl. Acad. Sci. U.S.A. 83, 8784-8788. doi:10.1073/pnas.83. 22.8784

Werling, L. L., Keller, A., Frank, J. G., and Nuwayhid, S. J. (2007). A comparison of the binding profiles of dextromethorphan, memantine, fluoxetine and amitriptyline: treatment of involuntary emotional expression disorder. Exp. Neurol. 207, 248-257. doi:10.1016/j.expneurol.2007.06.013

Weston, S., Coleman, C. M., Haupt, R., Logue, J., Matthews, K., Li, Y., et al. (2020). Broad anti-coronaviral activity of FDA approved drugs against SARS-CoV-
2 in vitro and SARS-CoV in vivo. J. Virol. 94, e01218-e01220. doi:10.1128/JVI. 01218-20

Wu, F., Zhao, S., Yu, B., Chen, Y.-M., Wang, W., Song, Z.-G., et al. (2020). A new coronavirus associated with human respiratory disease in China. Nature 579, 265-269. doi:10.1038/s41586-020-2008-3

Wu, Z., and Bowen, W. D. (2008). Role of sigma-1 receptor C-terminal segment in inositol 1,4,5-trisphosphate receptor activation. J. Biol. Chem. 283, 28198-28215. doi:10.1074/jbc.M802099200

Xue, M., Fu, F., Ma, Y., Zhang, X., Li, L., Feng, L., et al. (2018). The PERK arm of the unfolded protein response negatively regulates transmissible gastroenteritis virus replication by suppressing protein translation and promoting type I interferon production. J. Virol. 92, e00431-18. doi:10.1128/JVI.00431-18

Yan, Y., Zou, Z., Sun, Y., Li, X., Xu, K.-F., Wei, Y., et al. (2013). Anti-malaria drug chloroquine is highly effective in treating avian influenza A H5N1 virus infection in an animal model. Cell Res. 23, 300-302. doi:10.1038/cr.2012.165

Yang, H., Fu, Y., Liu, X., Shahi, P. K., Mavlyutov, T. A., Li, J., et al. (2017). Role of the sigma-1 receptor chaperone in rod and cone photoreceptor degenerations in a mouse model of retinitis pigmentosa. Mol. Neurodegener. 12, 68. doi:10.1186/ s13024-017-0202-z

Yang, H., Shen, H., Li, J., and Guo, L.-W. (2019). SIGMAR1/Sigma-1 receptor ablation impairs autophagosome clearance. Autophagy 15, 1539-1557. doi:10. 1080/15548627.2019.1586248

Yang, N., and Shen, H.-M. (2020). Targeting the endocytic pathway and autophagy process as a novel therapeutic strategy in COVID-19. Int. J. Biol. Sci. 16, 1724-1731. doi:10.7150/ijbs.45498

Yao, X., Ye, F., Zhang, M., Cui, C., Huang, B., Niu, P., et al. (2020). In vitro antiviral activity and projection of optimized dosing design of hydroxychloroquine for the treatment of severe acute respiratory syndrome coronavirus 2 (SARS-CoV2). Clin. Infect. Dis. 71, 732-739. doi:10.1093/cid/ciaa237

Yoshida, K., Takahashi, H., Sato, K., Higuchi, H., and Shimizu, T. (2000). Biperiden hydrochlorate ameliorates dystonia of rats produced by microinjection of sigma ligands into the red nucleus. Pharmacol. Biochem. Behav. 67, 497-500. doi:10. 1016/s0091-3057(00)00397-x

Zhai, M., Liu, C., Li, Y., Zhang, P., Yu, Z., Zhu, H., et al. (2019). Dexmedetomidine inhibits neuronal apoptosis by inducing Sigma-1 receptor signaling in cerebral ischemia-reperfusion injury. Aging 11, 9556-9568. doi:10.18632/aging.102404

Zhang, C., Zhang, Y., Qin, Y., Zhang, Q., Liu, Q., Shang, D., et al. (2019). Ifenprodil and flavopiridol identified by genomewide RNA interference screening as effective drugs to ameliorate murine acute lung injury after influenza A H5N1 virus infection. mSystems 4, e00431-19. doi:10.1128/mSystems.00431-19

Zhang, Y., Liu, R., Ni, M., Gill, P., and Lee, A. S. (2010). Cell surface relocalization of the endoplasmic reticulum chaperone and unfolded protein response regulator GRP78/BiP. J. Biol. Chem. 285, 15065-15075. doi:10.1074/jbc. M109.087445

Zhao, Z., Thackray, L. B., Miller, B. C., Lynn, T. M., Becker, M. M., Ward, E., et al. (2007). Coronavirus replication does not require the autophagy GeneATG5. Autophagy 3, 581-585. doi:10.4161/auto.4782

Zheng, K., Chen, M., Xiang, Y., Ma, K., Jin, F., Wang, X., et al. (2014). Inhibition of herpes simplex virus type 1 entry by chloride channel inhibitors tamoxifen and NPPB. Biochem. Biophys. Res. Commun. 446, 990-996. doi:10.1016/j.bbrc.2014.03.050

Zhou, Y., Hou, Y., Shen, J., Huang, Y., Martin, W., and Cheng, F. (2020). Networkbased drug repurposing for novel coronavirus 2019-nCoV/SARS-CoV-2. Cell Discov. 6, 14. doi:10.1038/s41421-020-0153-3

Zhu, N., Zhang, D., Wang, W., Li, X., Yang, B., Song, J., et al. (2020). A novel coronavirus from patients with pneumonia in China, 2019. N. Engl. J. Med. 382, 727-733. doi:10.1056/NEJMoa2001017

Conflict of Interest: JV was a full-time employee in ESTEVE PHARMACEUTICAS at the time of review.

Copyright (๑) 2020 Vela. This is an open-access article distributed under the terms of the Creative Commons Attribution License (CC BY). The use, distribution or reproduction in other forums is permitted, provided the original author $(s)$ and the copyright owner(s) are credited and that the original publication in this journal is cited, in accordance with accepted academic practice. No use, distribution or reproduction is permitted which does not comply with these terms. 